\title{
Investigation of the manoeuvrability characteristics of a Gate Rudder system using numerical, experimental, and full-scale techniques
}

\author{
Alessandro Carchen ${ }^{\mathrm{a} 1}$, Serkan Turkmen ${ }^{\mathrm{a}}$, Benedetto Piaggio ${ }^{\mathrm{b}}$, Weichao Shi ${ }^{\mathrm{a} 2}$, Noriyuki Sasaki ${ }^{\mathrm{c}}$, \\ Mehmet Atlar \\ aSchool of Engineering, Marine Technology Group, Newcastle University, Queen Victoria Road, Newcastle Upon Tyne, NE1 7RU, \\ UK \\ ${ }^{b}$ Department of Telecommunications, Electrical and Electronics Engineering and Naval Architecture, University of Genoa, Via \\ Montallegro 1, 16145, Genoa, IT \\ ${ }^{c}$ Department of Naval Architecture, Ocean \& Marine Engineering, Strathclyde University, 100 Montrose Street, Glasgow, G4 0LZ, \\ UK
}

The Gate Rudder is a recently introduced twin rudder system whose major advantages stem from its energy-saving properties. The two foil-shaped blades of the rudder, placed aside of the propeller, act as a partial duct in the wake of the hull producing additional thrust. However, since the rudder is a primary safety device on any vessel, investigating the manoeuvrability performance of the Gate Rudder is a critical aspect that needs careful and detailed consideration. Owing to its peculiar working principle and location, the standard manoeuvrability prediction methods cannot produce reliable results since they are applied to rudders acting behind the propellers.

This paper presents the first comprehensive investigation into the manoeuvrability performance of a Gate Rudder system, which includes the development of a modified MMG model, towing tank experiments and full-scale measurements. The modified MMG model was conceived to predict the manoeuvring motions of a ship with the Gate Rudder system. A generalised prediction method is defined based on this modified MMG model and detailed CFD analysis of the flow pattern around the Gate Rudder for two commercial hull-forms. The simulation model of the Gate Rudder is validated by means of towing tank tests and full-scale manoeuvring trials. The sea trials were conducted onboard two sister container vessels, the first fitted with the first-ever Gate Rudder system and the second with a high-performance flap rudder. This also allowed to compare the two different steering systems.

KEY WORDS: Gate Rudder; manoeuvrability; simulation; flap effect; MMG model; CFD simulation; full-scale trials

*Corresponding author: Alessandro Carchen, alessandro.carchen@edu.unige.it

\footnotetext{
${ }^{1}$ Permanent address: Department of Telecommunications, Electrical and Electronics Engineering and Naval Architecture, University of Genoa, Via Montallegro 1, 16145, Genoa, IT

${ }^{2}$ Permanent address: Department of Naval Architecture, Ocean \& Marine Engineering, Strathclyde University, 100 Montrose Street, Glasgow, G4 0LZ, UK
} 


\section{INTRODUCTION}

Over the years, Energy Saving Devices (ESDs) have been designed in the attempt to improve the propulsive efficiency of ships. Nowadays, the improvement of ship energy efficiency has a significant effect in mitigating the emissions of Green House Gases (GHG) from shipping. It is thus no wonder that ESDs are again attracting worldwide attention as means of reducing carbon emissions of complying with the Energy Efficiency Design Index (EEDI) and Ship Energy Efficiency Management Plan (SEEMP) regulations. ESDs are developed based on different hydrodynamic principles [1]-[3].

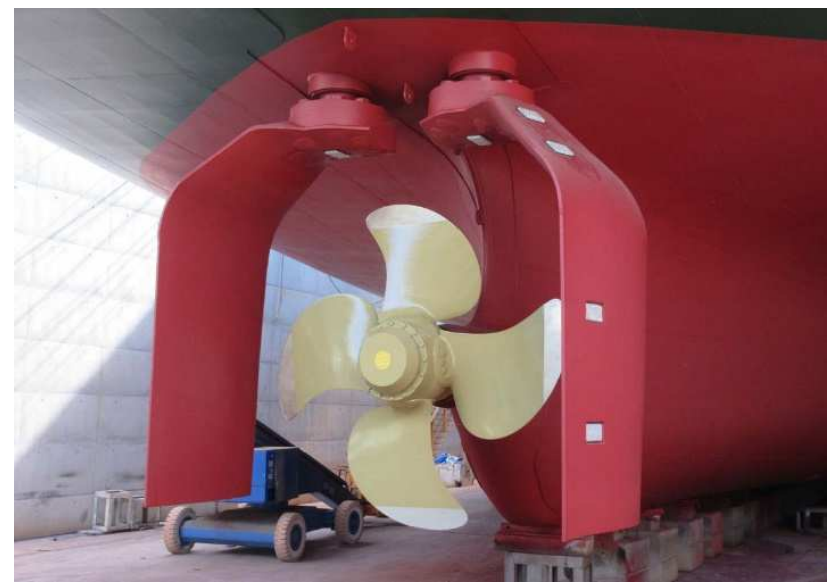

Figure 1. The first application of a Gate Rudder system

Broadly speaking, an ESD may target two aspects of energy recovery, the one related to the propeller rotational losses and the other to the viscous pressure resistance losses [3]. The Gate Rudder (GR) concept was first introduced by Sasaki [4] and aims at recovering part of the viscous resistance losses. It consists of a twin rudder system with two asymmetric section blades at each side of the propeller (Fig. 1). Essentially, the GR acts like a Conventional Rudder (CR), but it also improves the flow at and around the propeller by inducing an axial velocity in the propeller plane - the so-called 'duct effect'. This generates additional thrust and helps the recovery of the viscous resistance loss by equalising the ship's wake, thereby improving the propulsive efficiency [5], [6]. Therefore, the GR is based on principles similar to those exploited by the accelerating nozzles of ducted propellers.

Since the rudder is a primary safety device, the development strategy of the GR aims at improving the energy-saving capabilities of the ship as well as to preserve its safe manoeuvrability. It will be further shown in the paper that the GR well combines its ESD properties with excellent steering capabilities.

It is here useful to introduce the general rudder angle sign convention for the GR, which will be further detailed in Section 4. Figure 2 shows the two blades of the GR (here depicted as symmetric foils) aside the ship's propeller. The blades can rotate about the points marked by ' + ' bringing them closer to the hull (negative 'in' angles) of farther away from it (positive 'out' angles). This convention was adopted owing to the different rudder behaviour when in proximity or far from the hull. Maximum angles in either direction are indicated, although the GR operates in the range $-30 \sim+35$ deg for conventional manoeuvres at cruise speed (i.e. 10Z, 20Z, 35C etc.).

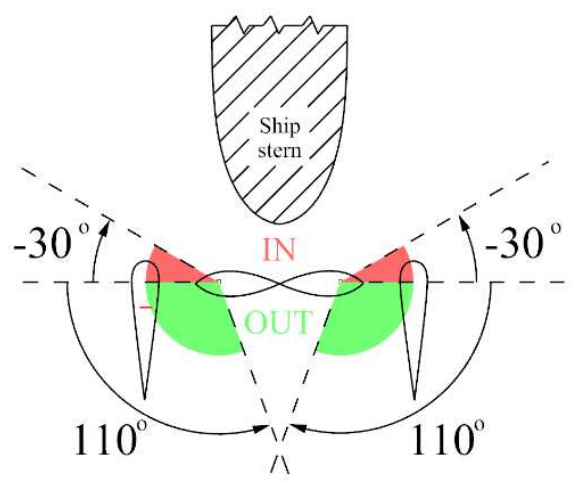

Figure 2. GR angle sign conventions and max angles

The two separate rudder stocks allow each of the twin rudder blades to be controlled to combine in several operational modes (Fig. 3). The unique manoeuvring modes of the GR are also described in Table 1, showing some of the possible modes to operate the rudder for an improved manoeuvrability and performance. The table shows the typical angles for port (PS) and starboard (STB) blades adopted for each mode. The first two modes indicate the static rudder angle range adopted during straight navigation - i.e. they don't show course keeping angles.

Table 1. Steering Modes of Gate Rudder

\begin{tabular}{|c|c|c|c|}
\hline \multirow[t]{2}{*}{ Name } & \multirow[t]{2}{*}{ Functions } & \multicolumn{2}{|c|}{ Rudder angle [deg] } \\
\hline & & $P S$ & $S T B$ \\
\hline $\begin{array}{l}\text { Economy } \\
\text { mode }\end{array}$ & $\begin{array}{l}\text { Most efficient } \\
\text { operation in calm sea } \\
\text { (straight navigation) }\end{array}$ & $+3 \sim+5$ & $+3 \sim+5$ \\
\hline $\begin{array}{l}\text { Rough sea } \\
\text { mode }\end{array}$ & $\begin{array}{l}\text { Propeller speed can } \\
\text { be increased by the } \\
\text { accelerated flow } \\
\text { (straight navigation) }\end{array}$ & $+0 \sim+2$ & $+0 \sim+2$ \\
\hline $\begin{array}{l}\text { Steering } \\
\text { mode }\end{array}$ & $\begin{array}{l}\text { Normal course } \\
\text { change (to stb.) }\end{array}$ & +10 & -10 \\
\hline Circle mode & $\begin{array}{l}\text { Emergency steering } \\
\text { (to stb.) }\end{array}$ & -30 & +35 \\
\hline $\begin{array}{l}\text { Crash Stop } \\
\text { mode }\end{array}$ & $\begin{array}{l}\text { Emergency crash stop } \\
\text { (straight motion) }\end{array}$ & -30 & -30 \\
\hline $\begin{array}{l}\text { Crabbing } \\
\text { mode }\end{array}$ & $\begin{array}{l}\text { Berthing \& de- } \\
\text { berthing (to stb.) }\end{array}$ & +110 & +60 \\
\hline
\end{tabular}

A most interesting feature of the GR is the crabbing mode, seen in the bottom right impression in Fig. 3, whereby the GR generates strong side forces that can be used in low speed ship berthing in replacement of stern thrusters. In addition to these benefits, the improvement of the stern flow can reduce the flow-induced noise and vibration [7], [8]; the duct effect helps mitigating the propeller cavitation [7], [8]; and the position of the GR stocks (more forward than CRs') allows to increase the cargo space, or decreasing the ship length, on single-screw ships [3]. 
Table 2. Research on the manoeuvrability of Gate Rudder

\begin{tabular}{|c|c|c|}
\hline Name & Contents & Facility etc. \\
\hline Tank Tests & $\begin{array}{l}\text { Rudder force } \\
\text { measurements } \\
\text { with } 6 \mathrm{~m} \text { Large } \\
\text { ship model } \\
\text { (without yaw } \\
\text { angle); } \\
\text { Hull force } \\
\text { measurements } \\
\text { with } 2 \text { m Ship } \\
\text { model; } \\
\text { Captive tests and } \\
\text { free-running tests } \\
\text { with } 2.5 \mathrm{~m} \text { ship } \\
\text { model }\end{array}$ & $\begin{array}{l}\text { NMRI, } \\
\text { FEL and } \\
\text { Kyushu Uni. }\end{array}$ \\
\hline Simulation & $\begin{array}{l}\text { Development of } \\
\text { simulation } \\
\text { program based on } \\
\text { MMG model } \\
\text { rudder control } \\
\text { system. }\end{array}$ & $\begin{array}{l}\text { Newcastle } \\
\text { University, } \\
\text { Strathclyde } \\
\text { University, } \\
\text { Kamome } \\
\text { Propeller \& } \\
\text { Tokyo Keiki }\end{array}$ \\
\hline Full-Scale Tests & $\begin{array}{l}\text { Manoeuvring tests } \\
\text { at sea trials; } \\
\text { Monitoring at } \\
\text { after delivery }\end{array}$ & $\begin{array}{l}\text { Yamanaka } \\
\text { Shipyard, } \\
\text { Strathclyde } \\
\text { University \& } \\
\text { Newcastle } \\
\text { University }\end{array}$ \\
\hline
\end{tabular}

In contrast to the GR, a typical Conventional Rudder (CR) normally entails the following disadvantages on singlescrew ships:

- $\quad$ additional appendage drag;

- necessary stern arrangement to accommodate the rudder, which enforces restriction not only to the propeller diameter but also to the engine room arrangement;

- a non-uniform flow imposed on the propeller plane that can easily increase the vibration and noise originating not only from the propeller but also from the propeller-rudder interaction;

- propeller cavitation erosion on the rudder;

- poor course keeping for beamy ships with a displacement to length ratio $\nabla^{1 / 3} / L>0.2$ [9].

Recent studies also revealed that the GR system produces a significant 'flap effect', which improves the manoeuvring efficiency by exploiting the hull-rudder interaction [3]. Equation 1 explains the flap effect in terms of the total rudder side force $\left(Y_{R}\right)$ :

$$
Y_{R}=\left(1+a_{H}\right) F_{Y}
$$

where $F_{Y}$ is the side force generated by the rudder alone and $a_{H}$ is the so-called 'rudder force increase factor' caused by the interaction of the hull-propeller-rudder system. Therefore, $a_{H} F_{Y}$ represents the additional lift generated on the stern section of the hull. $a_{H}$ was introduced in the theoretical model of Manoeuvring Modelling Group (MMG) [10] and depends on the distance between the hull and the rudder, the hull form and the overall hull-propeller-rudder arrangement [11]-[13]. This phenomenon is also observed on CR. Average values of $a_{H}$ for conventional rudders vary between $0.1-0.4$ in general [11], [12].

Several studies have been hitherto conducted to investigate the GR propulsive performance, e.g. [4], [6], [14], manoeuvring characteristics, e.g. [15]-[17], and structural responses [5]. Current research involves scale effects, hullpropeller-rudder interaction, structural integrity and vibration, which is of particular interest given the unique shape of the GR. As reported in some of these investigations, if the recent research has improved the manoeuvring prediction methods by introducing a generalised definition of the flow field around the rudder, the latest manoeuvring trials of the first GR system application on a full-scale container vessel have provided confirmation of the initial numerical estimation of its performance [5], [18].

In the light of these recent developments, listed in Table 2, this paper investigates the manoeuvrability performance of the GR system to demonstrate its suitability as steering system and complement its ESD characteristics. The following objectives are set to achieve this aim:

a) Review of the current manoeuvrability theory expressed by the MMG prediction model;

b) Investigation of the flow field in the operating region of a GR system using CFD simulations on two commercial hull-forms;

c) Development of a manoeuvrability model based on a modified MMG model and suitable for the prediction of the manoeuvrability performance of GR systems;

d) Model-scale validation of the numerical prediction utilising towing tank tests, and

e) Full-scale validations of a GR system installed on a container ship (Fig. 1) and comparison of its performance with a sister vessel (i.e. same hull) fitted with a high-lift flap-rudder (FR) system based on dedicated manoeuvrability trials.

Finally, Table 3 presents the main characteristics of the two ships presented and used in the analyses of this paper.

The remaining of the paper is structured as follows. Section 2 describes the principles of the MMG model, which is used as basis for the proposed manoeuvrability analysis of the GR. Section 3 presents the CFD simulations that have been conducted to obtain the velocity field in the rudder area. Section 4 details the modified MMG manoeuvrability prediction method, which includes the velocity gradient estimation from Section 3 and towing tank measurements. Then, Section 5 presents the results of the full-scale manoeuvrability trials, which were conducted on two twin 
sister ships - the one fitted with a flap-rudder the other with the first ever GR system. Finally, conclusions and recommendations are given in Section 6.

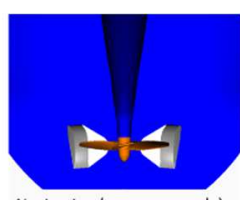

Navigation (economy mod Rudder angle $+3 \sim+5$ deg.

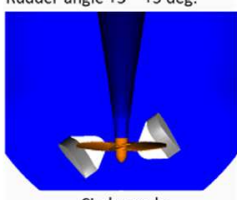
Circle mode
Rudder angle $-30 \&+35$ de

Figure 3. Steering Modes of Gate Rudder

Table 3. Main details of the ships used in this paper

\begin{tabular}{|l|c|c|c|}
\hline Ship type & $\begin{array}{c}\text { Domestic } \\
\text { Cargo }\end{array}$ & \multicolumn{2}{|c|}{ Feeder Container } \\
\hline Scope & $\begin{array}{c}\text {-Model tests } \\
\text {-Prediction }\end{array}$ & $\begin{array}{c}\text {-FS trials } \\
\text {-Prediction }\end{array}$ & $\begin{array}{l}\text {-FS trials } \\
\text {-Prediction }\end{array}$ \\
\hline Lpp $(m)$ & 68.6 & \multicolumn{2}{|c|}{101.9} \\
\hline$B(m)$ & 12 & \multicolumn{2}{|c|}{17.8} \\
\hline$d(m)$ & 4.19 & \multicolumn{2}{|c|}{5.25} \\
\hline $\begin{array}{l}\text { Design } \\
\text { Speed }(k n)\end{array}$ & 12.8 & \multicolumn{2}{|c|}{15.5} \\
\hline Rudder & GR & FR & GR \\
\hline
\end{tabular}

\section{THE MMG PREDICTION MODEL}

The MMG standard prediction method is a nonlinear ship manoeuvring mathematical model developed by the Japanese Manoeuvring Modelling Group [19] and later standardised by the Japan Society of Naval Architects and Marine Engineers (JSNAOE)[10], [20]. The standard is composed of four parts, namely:

- Mathematical manoeuvrability model

- Procedure to conduct the required captive model tests

- Procedure to analyse the model tests

- A full-scale manoeuvrability prediction method

The fundamentals of the first shall be here recalled. The reference coordinate system for the ship adopted by the MMG model is defined as in Figure 4.

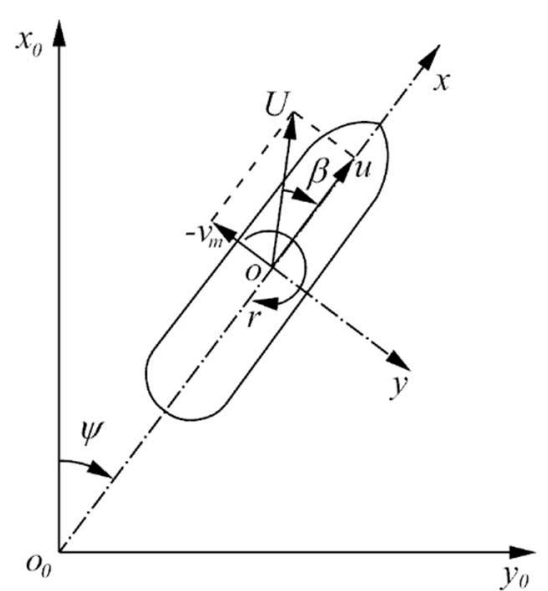

Figure 4. Ship reference coordinate system

where $x_{0}$ and $y_{0}$ lay on the still water surface, $o$ coincides with the midship point, $u$ and $v_{m}$ is the axial and normal component of the ship velocity $U$ along the ship axis, respectively, $r$ is the yaw rate and $\beta$, and $\psi$ correspond to the drift and heading angles, respectively. The drift angle is defined as:

$$
\beta=\tan ^{-1}\left(-\frac{v_{m}}{u}\right)
$$

Neglecting the added mass coupling terms, the ship motion equations are defined accordingly in the surge $(X)$, sway $(Y)$ and yaw $(Z)$ directions:

$$
\left\{\begin{array}{l}
X=\left(m+m_{x}\right) \dot{u}-\left(m+m_{y}\right) v_{m} r-x_{G} m r^{2} \\
Y=\left(m+m_{y}\right) \dot{v}_{m}+\left(m+m_{x}\right) u r+x_{G} m \dot{r} \\
N=\left(I_{z}+J_{z}\right) \dot{r}+x_{G} m\left(\dot{v}_{m}+u r\right)
\end{array}\right.
$$

where $m, m_{x}, m_{y}$ are the mass and added mass terms in $x$ and $y$ direction, respectively and $I_{z}$ is the moment of inertia about the $z$ axis. According to the MMG model, the acting forces and moments are subdivided in the lateral plane as follows:

$$
\left\{\begin{array}{l}
X=X_{H}+X_{R}+X_{P} \\
Y=Y_{H}+Y_{R} \\
N=N_{H}+N_{R}
\end{array}\right.
$$

where subscripts $H, P$ and $R$ refer to Hull, Propeller and Rudder related forces, respectively.

As customary, forces are non-dimensionalised by $0.5 \rho U^{2} L d$ and moments by $0.5 \rho U^{2} L^{2} d$, where $L$ and $d$ are the ship length between perpendiculars and draught, respectively. Nondimensional forces and moments are denoted by the conventional prime'. The hull forces and moments are expressed as functions of the velocity $U$ of the vessel, its drift angle $\beta$ and yaw rate $r$ with uncoupled and coupled terms up to the third order: 


$$
\left.\begin{array}{c}
X_{H} \\
Y_{H} \\
N_{H}
\end{array}\right\}=f(U, \beta, \dot{\beta}, r, \dot{r},)
$$

The relationships with these variables depend on the geometry of the vessel, and it is, therefore, recommended to use captive model tests, computational estimations, or other expedients to obtain the manoeuvrability derivatives. If none of these suggested solutions is available, statistical regressions may be used for common hull forms such as described in [21].

Propeller forces are considered in the longitudinal direction only, neglecting the transverse forces and moments acting on the propeller as the property of single screw vessels. The customary representation for the propeller characteristics is used to calculate the propeller thrust coefficient $K_{T}$, keeping into account the change in the Taylor wake fraction, $w_{P}$, and thrust due to the manoeuvring motion. $K_{T}$ is represented as a second-order polynomial function of the propeller advance coefficient $J_{P}$.

The MMG original sign convention for the rudder-related variables is represented in Fig. 5, where $U_{R}=\sqrt{u_{R}^{2}+v_{R}^{2}}$, is the inflow velocity at the rudder, with $u_{R}$ and $v_{R}$ its components on the ship coordinate system; $\alpha_{R}$ is the inflow angle and $\delta$ is the rudder angle.

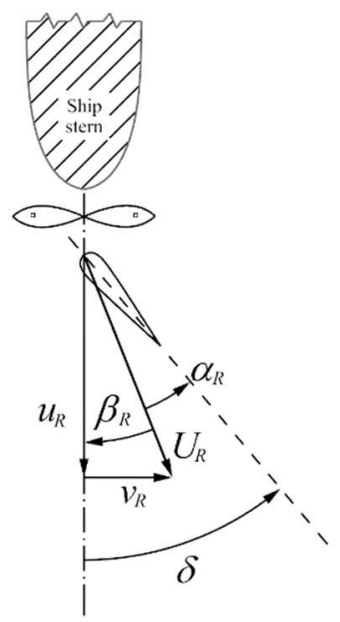

Figure 5. Rudder inflow velocities and angles

The hydrodynamic rudder forces $\left(X_{R}, Y_{R}, N_{R}\right)$ are presented as the sum of two fundamental components, namely the lift force acting on the rudder itself and the additional lift force induced on the hull by the rudder-hull interaction given in Equation (6):

$$
\left\{\begin{array}{l}
X_{R}=-\left(1-t_{R}\right) F_{N} \sin \delta \\
Y_{R}=-\left(1+a_{H}\right) F_{N} \cos \delta \\
N_{R}=-\left(x_{R}+a_{H} x_{H}\right) F_{N} \cos \delta
\end{array}\right.
$$

where $F_{N}$ represents the rudder normal force, $t_{R}$ the change in drag due to rudder-propeller interaction, $a_{H}$ the rudder force increase factor, $x_{R}$ the longitudinal position of the rudder from midship and $x_{H}$ the longitudinal position of the acting point of the additional lateral force component from mid-ship. The rudder normal force is defined by equation (7) as follows [10]:

$$
F_{N}=0.5 \rho A_{R} U_{R}^{2} f_{\alpha} \sin \alpha_{R}
$$

where $A_{R}$ is the rudder projected area and $f_{\alpha}$ the lift gradient coefficient.

In the MMG model, $\alpha_{R}$ and $v_{R}$ are calculated with consideration of the complex flow straightening phenomena related to the hull wake and propeller slipstream during any manoeuvre as follows. In analogy with eq. (2) the local drift angle at the rudder is defined as:

$$
\beta_{R}=\tan ^{-1}\left(-\frac{v_{R}}{u_{R}}\right)
$$

The inflow angle at the rudder is the described as [10]:

$$
\alpha_{R}=\delta+\beta_{R}
$$

where $\delta$ is the helm angle. Assuming that the helm angle is zero when $\beta$ and $r^{\prime}$ are small, $v_{R}$ is described as [10]:

$$
v_{R} \approx U \gamma_{R} \beta_{R}^{*}
$$

where $\gamma_{R}$ is the flow straightening coefficient that describes the flow straightening phenomenon originated by the hull and propeller slipstream in front of the rudder (Fig. 5). $\beta_{R}^{*}$ is the drift angle at the rudder neglecting the flow straightening effect and it is defined as the algebraic sum of the ship drift angle $\beta$ and that locally induced by the ship's yaw motion:

$$
\beta_{R}^{*}=\beta-\ell^{\prime}{ }_{R} r^{\prime}
$$

with $\ell_{R}^{\prime}$ representing the longitudinal distance of the rudder from midship, though it is fundamentally obtained from captive model tests [10]. $r^{\prime}$ is the ship's nondimensional yaw rate. To take into account the propeller slipstream velocity, $u_{R}$ is instead calculated as [10]:

$$
u_{R}=\varepsilon u\left(1-w_{P}\right) \sqrt{\eta\left[1+\kappa\left(\sqrt{1+\frac{8 K_{T}}{\pi J_{P}^{2}}}-1\right)\right]^{2}+(1-\eta)}
$$

where $\varepsilon$ is the ratio of wake fraction at rudder and propeller positions, $\eta$ is the ratio of propeller diameter to rudder span, and $\kappa$ is an experimental constant.

The original MMG formulation hitherto presented can only be used for common rudders in a behind-propeller configuration. The particular geometry and location of the GR would require additional considerations. The first 
implication of its uncommon features would be associated with the inflow characteristics, due to its close proximity to the hull and the propeller disc. This, in turn, will affect the interaction with the hull during turning manoeuvres (flap effect). Finally, because of its unique mechanism, many steering modes can be explored, and its helm control must be defined differently.

Owing to the characteristics described above and the limited number of variables, the MMG standard prediction method needs to be modified prior to be implemented in a GR manoeuvrability simulation program. The modifications should be conducted with an understanding of the flow characteristics around the Gate Rudder and applying a suitable correction to the method with the aid of CFD simulations which are described in the next section.

\section{CFD SIMULATIONS}

The modelling of the flow field around the hull and GR system provides a challenge. Rare numerical studies have been conducted to investigate the effective wake aside of the propeller under various drift angle conditions at the locations of interest in this study. To understand and predict the flow velocity distribution for the Gate Rudders, a full-scale Computational Fluid Dynamics (CFD) model was established for two different hull-forms, namely a domestic cargo and a feeder container. The numerical experiment is conducted placing the hull in a flow with velocity equal to the ship's design speed. The incidence angle of the flow (i.e. drift angle) is then varied systematically. The numerical model in this paper was built in the commercial CFD software Star-CCM+ to solve the Reynolds Averaged Navier-Stokes (RANS) equations with Shear Stress Transport (SST) turbulence models. The simulations were conducted without the free surface to neglect its limited impact on the effective wake. The meshes were generated with a first element thickness equating to $\mathrm{y}^{+}=2$ with 10 elements in the boundary layer. The total number of cells was approximately $1.2 \mathrm{M}$. The origin of the computation domain is the centre of the rudder stock, located at $\mathrm{x}=0$ and $\mathrm{y}=0$ and the ship's waterline is at $\mathrm{z}=0$. The domain extends in the longitudinal direction $(\mathrm{x})$ from $-2 L p p$ to $2 L p p$, lateral direction (y) from $-1 L p p$ to $1 L p p$ and vertical direction (z) from 0 to $-1 L p p$.

The propeller slipstream cannot, however, be ignored, and a virtual disc model at the propeller position has thus been included, where the virtual disc can simulate the propeller flow without an actual propeller modelling. The body force propeller method was chosen as part of the virtual disk model. Thus, the propeller performance characteristics (thrust, torque, and advance speed) were introduced in the CFD model by providing the propeller open water curve and correct operating condition to maintain the required thrust to overcome the vessel's resistance [22]. Because of the objective of the computation, the Gate Rudder geometries were not included in the CFD analysis. This acceptable simplification is dictated by the need to obtain the velocity field at all possible angles that may be assumed by the GR blades. The transverse velocity at the rudders will therefore be described as the superposition of two components, namely a pure drift component (CFD) and a rotational component - this is described in more detail in Section 4. The influence of the GR blades on the inflow velocities is object of current study. Therefore, the hullrudder-propeller interaction was not included directly in the CFD calculations, but it is considered in the manoeuvring model with the rudder force increase factor $\left(a_{H}\right)$ and the position of the additional lateral force $\left(x_{H}\right)-$ see Section 4. A fixed cylindrical probe covering all the possible GR angles was defined (Fig. 6). The cylindrical surface represents the region where the rudders are operated, and where the inflow velocities are calculated. Theta $(\theta)$ is the angular coordinate on the cylinder and varies between 0 and 360 degrees. Figure 7 shows the definition of $\theta$ on the cylindrical probe together with the range of operation of the GR in the standard manoeuvres simulated in this paper. The figure also shows the maximum, minimum and amidships positions of the GR blades as dotted figures. It will be appreciated that although the probe differs from the trajectory of the GR blades for large rudder angles, the approximation is acceptable for the shown range of operation. The conditions of the CFD simulation are specified in Table 4 which represents the

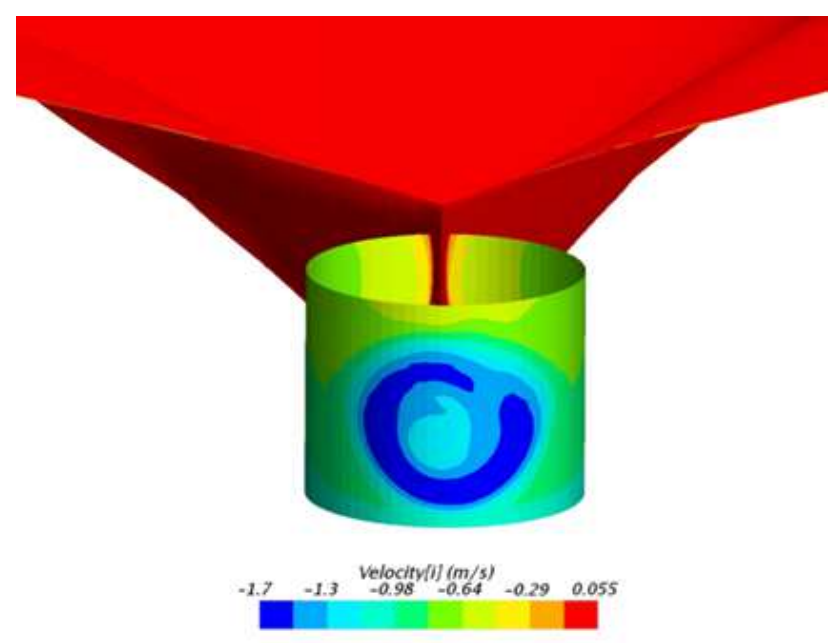

actual operational profiles.

Figure 6. The cylindrical probe

The trimmer mesh generator in Star-CCM+ has been used with prismatic boundary layer mesh control and volumetric mesh control. In total, about 2 million cells have been used in the computational domain. During the simulation, the k$\omega$ Shear Stress Transport (SST) turbulence model was preferred. A velocity inlet with oblique flow angle and pressure outlet were applied for the inlet and outlet boundary conditions, while a free-slip wall condition was applied to the bottom boundary. 


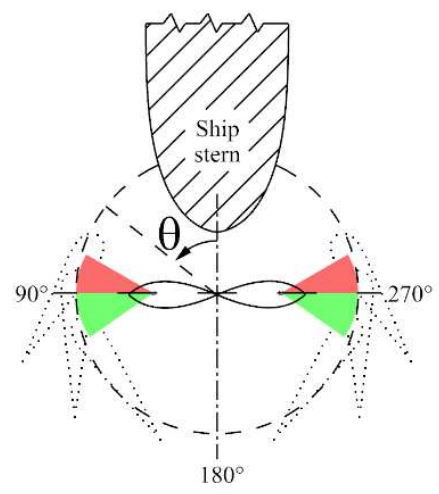

Figure 7. Angular coordinate of the probe, $\theta$. In red and green the in and out GR angles in standard manoeuvres

Table 4. CFD simulation conditions

\begin{tabular}{|l|l|}
\hline Ship speed & Design speed \\
\hline Propeller operation & Constant thrust \\
\hline Drift angles & $0^{\circ}$ to $16^{\circ}\left(2^{\circ}\right.$ intervals $)$ \\
& $25^{\circ}$ and $35^{\circ}$ \\
\hline
\end{tabular}

The flow velocity distributions at all Gate Rudder positions were thus calculated for the two vessels. Figures 8 through 11 display representative results for the Domestic Cargo vessel simulations. Figure 8 shows the velocity distribution of the section at the propeller position together with the velocity vectors at the $0^{\circ}$ helm angle of Gate Rudder position when the drift (oblique) angle is $0^{\circ}$. The flow is nearly symmetric to the mid-ship, but not exactly, due to the rotational effect of this right-handed propeller model. It is also clear that in the GR position shown by the vectors the flow velocity is much closer to the free-stream velocity than abaft the propeller. When steered, the GR operates in both regions, and this must be taken into account. Figure 9 shows the same results from the top view of the shaft line section. Another result presented is for the case of $16^{\circ} \mathrm{drift}$ to portside (i.e. $16^{\circ}$ oblique inflow in the CFD model). The same post-analysis was conducted, which is presented in Fig. 10 and Fig. 11. Because of the drift effect, the velocity distribution is strongly biased, especially on the starboard side where the flow is decelerated due to being in the hull's shadow.

Hence, the numerically calculated velocities $u_{R}$ and $v_{R}$ of the computational domain were averaged along the virtual span of the GR for the range of possible helm angles at each drift angle $(\beta)$ from $0^{\circ}$ to $35^{\circ}$. These velocities were normalised by the ship's speed $U$ and will be hereafter denoted by $u_{R}^{\prime}$ and $v_{R}^{\prime}$. Multiple regression analysis was then used to estimate the normalised velocities as polynomial functions of the drift angle $\beta$ and helm angle $\delta$, as explained in detail in the next section.

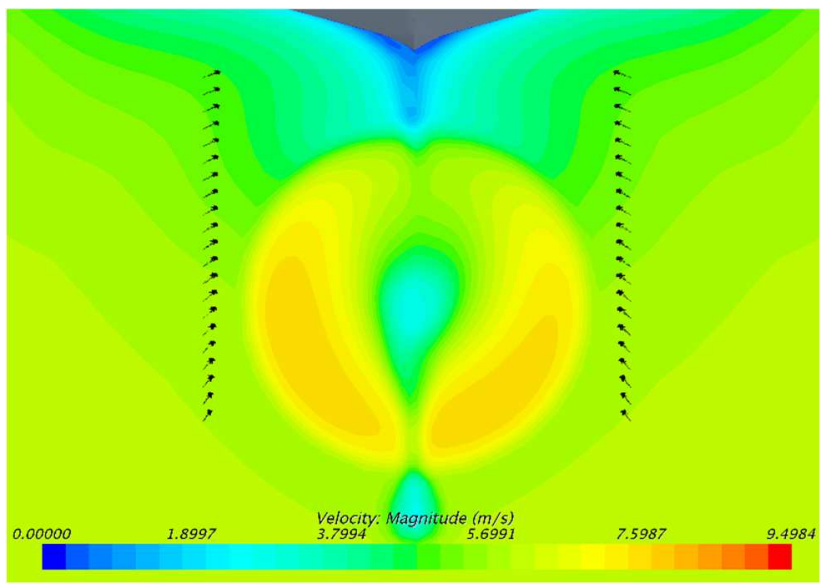

Figure 8. Velocity and vector distribution at 0deg oblique angle (aft view)

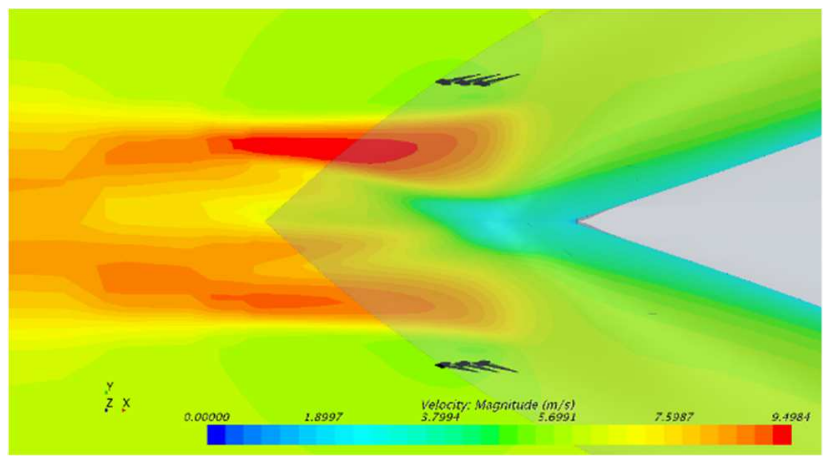

Figure 9. Velocity and vector distribution at 0deg oblique angle (top view)

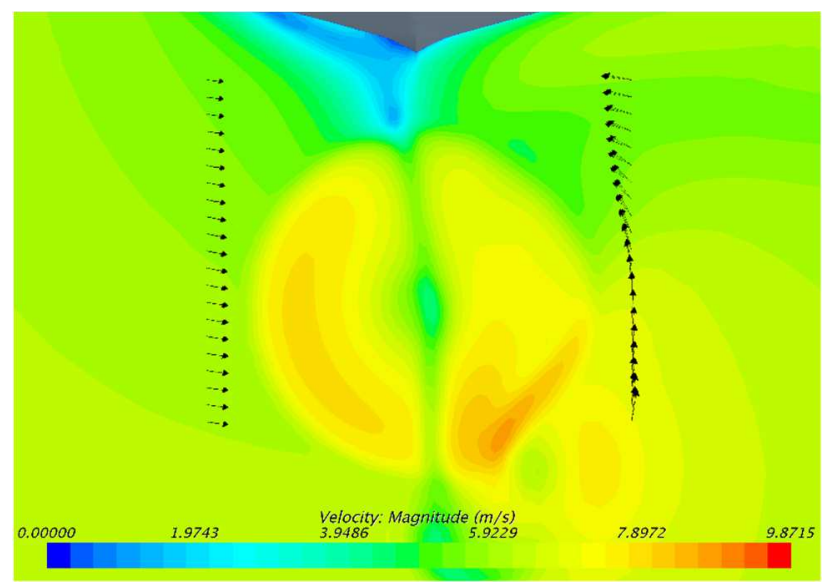

Figure 10. Velocity and vector distribution at 16deg oblique angle (aft view) 


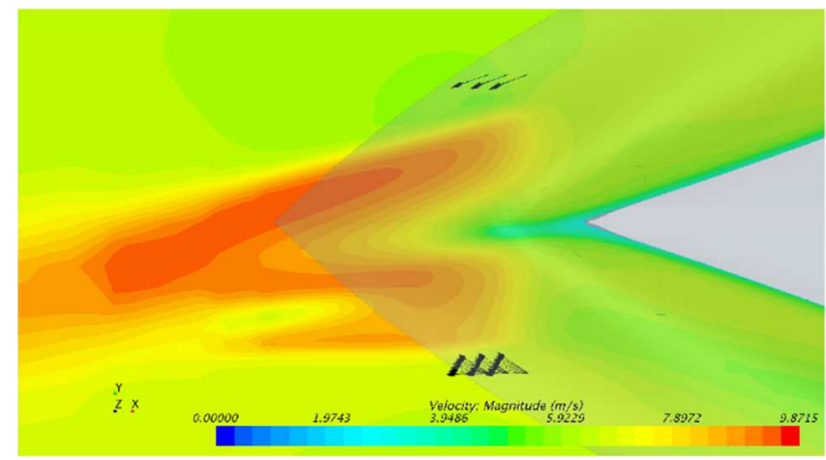

Figure 11. Velocity and vector distribution at $16 \mathrm{deg}$ oblique angle (top view)

\section{MANOEUVRABILITY PREDICTION MODEL}

In this section, the adaptation of the MMG manoeuvrability model to the GR system is described. The reference coordinate system for the ship is the same as in the original MMG model (Fig. 4).

The different hydrodynamic conditions to which the GR is subjected had to be initially addressed. Firstly, new parameters were defined to address the inflow components and the peculiar rudder angles assumed by the GR. These are shown in Fig. 12 in analogy with Fig. 5. Here, the subscripts $P$ and $S$ address the Port and Starboard blade, respectively. For convention, by taking the vertical plane passing through the propeller blade tips as reference, the rudder angles closer to the hull (in) are negative, those farther from the hull (out) are positive.

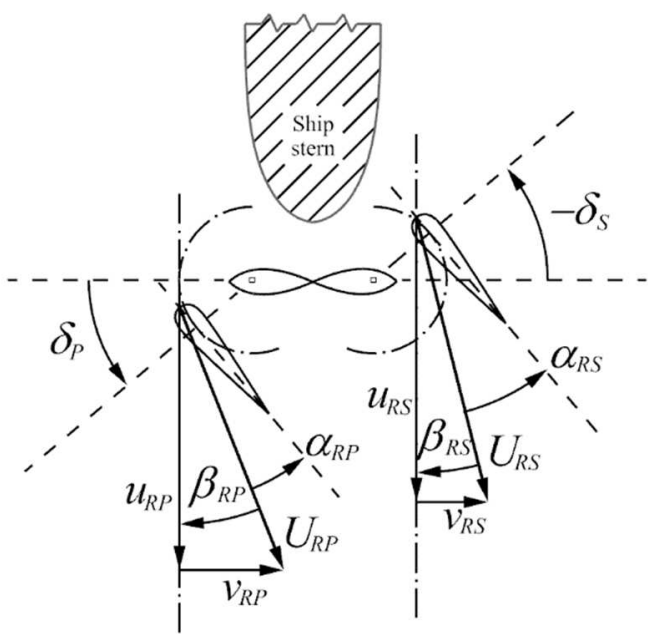

Figure 12. Inflow parameters for the Gate Rudder

Secondly, the calculation of the total forces and moments had to be revised. These are calculated as:

$$
\left\{\begin{array}{l}
X_{R}=X_{R P}+X_{R S} \\
Y_{R}=Y_{R P}+Y_{R S} \\
N_{R}=N_{R P}+N_{R S}
\end{array}\right.
$$

where similarly to Equation (6):

$$
\begin{aligned}
& X_{R P}=-\left(1-t_{R}\right) F_{N P} \sin \left(\delta_{P}\right) \\
& X_{R S}=-\left(1-t_{R}\right) F_{N S} \sin \left(-\delta_{S}\right) \\
& Y_{R P}=-\left(1+a_{H P}\right) F_{N P} \cos \left(\delta_{P}\right) \\
& Y_{R S}=-\left(1+a_{H S}\right) F_{N S} \cos \left(-\delta_{S}\right) \\
& N_{R P}=-\left(x_{R}+a_{H P} x_{H}\right) F_{N P} \cos \delta_{P} \\
& N_{R S}=-\left(x_{R}+a_{H S} x_{H}\right) F_{N S} \cos \left(-\delta_{S}\right)
\end{aligned}
$$

The forces, induced forces, rudder position $\left(x_{R}\right)$ and position of the additional lateral force $\left(x_{H}\right)$ generated by the GR are depicted in Fig. 13 for the port side blade only. Hence, the inflow velocity components needed to be calculated to obtain the inflow angle and in turn the rudder force. Here, the main difference from a CR stems from the flow region where the GR operates. The GR is positioned outside of the hull's boundary layer aside of the propeller and it operates partly in the propeller slipstream and partly outside of it. This means that the inflow at the rudder blades strongly depends on the helm angle $\delta$. As observed in the previous section, the magnitude of the inflow velocity at helm angles close to $0^{\circ}$ during straight navigation is almost the same as the ship speed. As soon as the rudder blade moves toward the propeller slipstream (out), it will be partially affected, or covered, by velocity gradients higher than the free-stream velocity, as shown in Fig. 13. This complex phenomenon must be accurately described to predict the forces on the GR.

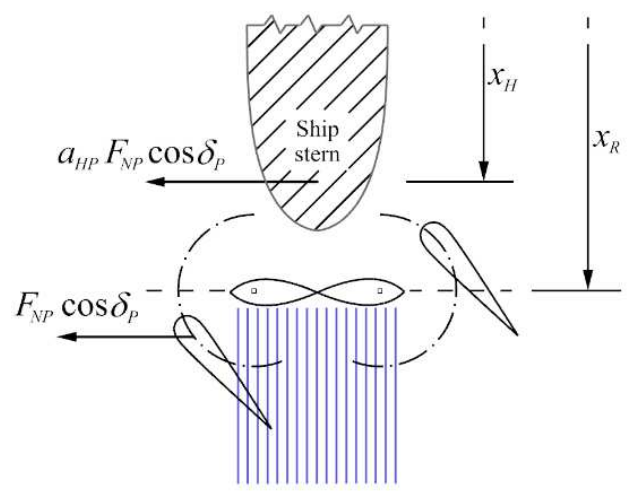

Figure 13. Forces and induced forces of the port GR blade, partially in the propeller slipstream. Dimensions from midship

The CFD results of the two hullforms allowed the derivation of generic parametric equations describing the non-dimensional inflow velocity components at the rudder considering this principle. The axial velocity at the rudder can be calculated from two velocity components, namely:

1. Behind the hull free-stream velocity with pure drift angle, and

2. Propeller slipstream velocity affected by wake fraction variation 
This concept has been confirmed without assumptions by the CFD results and the key issue is becoming to define the exposure (or 'coverage factor') of the GR blades to the second velocity component. The covered area ratio $\mu$ can be calculated based on the following equation:

$$
\mu=\frac{A_{C V}}{A_{R} \cdot \eta}
$$

Where $A_{R}$ is the rudder blade area, $\eta$ the ratio of propeller diameter to rudder span and $A_{C V}$ is the rudder area inside the propeller slipstream. Figure 14 shows a simplified drawing of the port GR blade partially covered by the propeller slipstream.

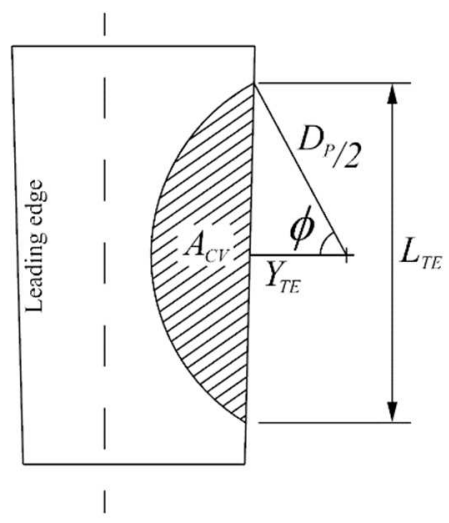

Figure 14. Covered area definitions

Let $D_{P}$ be the propeller diameter, $\delta$ the GR helm angle and $Y_{T E}$ the transverse position of the trailing edge of the GR blade respectively. Then:

$$
\begin{aligned}
& L_{T E}=\left\{\begin{array}{cl}
0 & \text { if } \delta<0 \vee Y_{T E}>\frac{D_{P}}{2} \\
2 \sqrt{\frac{D_{P}^{2}}{4}-Y_{T E}^{2}} & \text { elsewhere }
\end{array}\right. \\
& \phi_{T E}=\tan ^{-1}\left(\frac{L_{T E}}{2 Y_{T E}}\right)
\end{aligned}
$$

Then, the covered area can be approximated by the following equation:

$$
A_{C V} \approx \phi_{T E} \frac{D_{P}^{2}}{4}-\frac{Y_{T E} L_{T E}}{2}
$$

Having defined the covered area ratio, parametric definitions of the velocity components at the rudder blades were sought based on the CFD results. Figure 15 shows, for three drift angles, the nondimensional axial flow velocities calculated by CFD against the angular coordinate $\theta$ of the cylindrical probe defined in Fig. 7.

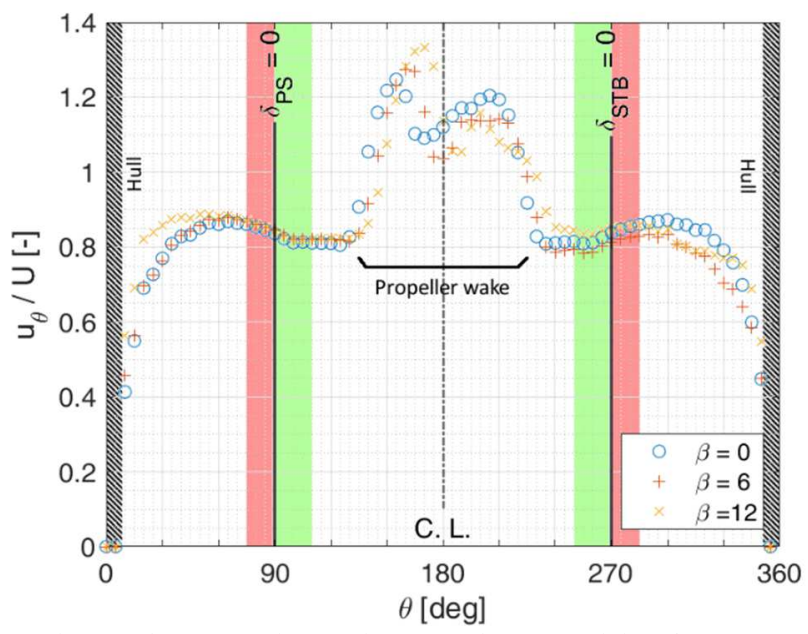

Figure 15. Nondimensional axial velocities for the Domestic Cargo at three drift angles on the cylindrical probe. Ship centreline, amidships position of each GR blade and hull position (shaded) are shown. In red and green the in and out GR angles in standard manoeuvres

The ship centreline passes through $\theta=180$. The hatched areas at $0<\theta<5$ and $355<\theta<360$ show the position of the stern of the hull. The rudder amidships position for the port and starboard blades, respectively named as $\delta_{P S}=$ 0 and $\delta_{S T B}=0$, are shown with vertical lines. The GR angles in normal operation are also shown in red and green in analogy with Fig. 7 . When the rudder blades operate outside of the propeller slipstream (circa $60<\theta<120$ for Port and $240<\theta<300$ for Starboard, both corresponding to approximately $-30<\delta<30$ ) the drift angle has a smaller effect on the axial velocity, and consequently the velocity profile can be described as a mere function of $\theta$, which can be related to the helm angle $\delta$ of the GR. When the rudder blades operate in the propeller slipstream (circa $120^{\circ}<\theta<240^{\circ}$ ), the axial velocity can instead be related directly to the propeller loading coefficient. Figure 16 shows a comparison of the non-dimensional axial velocities for the Domestic Cargo vessel and the container ship at the same three drift angles. Depending on the operating region, the velocity profiles can be similar for both vessels. 


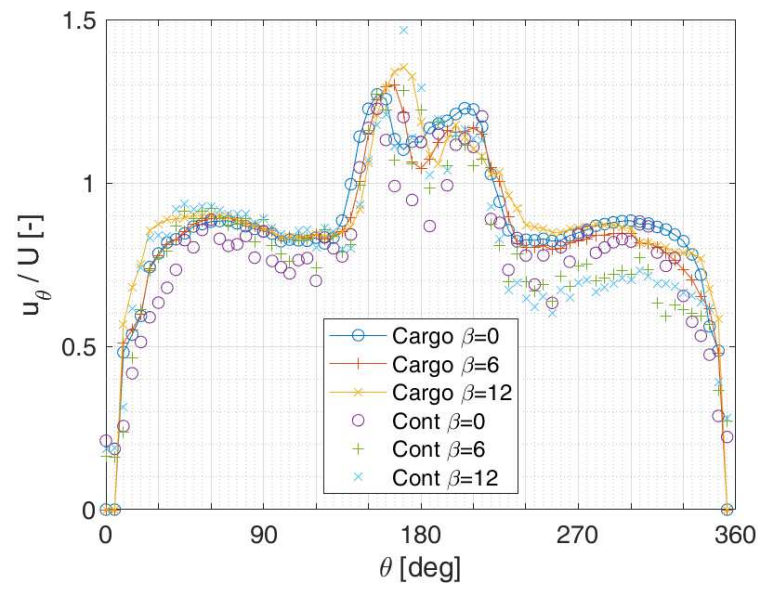

Figure 16. Nondimensional axial velocities on the probe of Domestic Cargo and Container vessel at three drift angles

From the comparison of the axial velocity characteristics of the two hullforms, it was concluded that the two velocity components can be calculated with the same equations for vessels with similar hull shape. Therefore, the inslipstream nondimensional axial velocity component on any rudder blade, $u_{\text {Ris }}^{\prime}$, can be calculated with an equation that uses the same principle of the original MMG equation, (12), after the introduction of the concept of covered area. The nondimensional axial velocity component outside of the slipstream on the port and starboard blades, $u_{R P o s}^{\prime}$ and $u_{R S o s}^{\prime}$ respectively, are described for simplicity as bare functions of the GR port and starboard angles. The inside and outside components are expressed in Equations (19) and (20):

$$
\begin{aligned}
& u_{\text {Ris }}^{\prime}=\varepsilon\left(1-w_{P}\right)\left[1+\mu \sqrt{1+\frac{8 K_{T}}{\pi J_{P}^{2}}}\right] \\
& u_{R P o s}^{\prime}=0.85-0.0859 \cdot \delta_{P} \\
& u_{R S o s}^{\prime}=0.85+0.0859 \cdot \delta_{S}
\end{aligned}
$$

where the rudder angle is expressed in radians.

A similar investigation was carried out for the nondimensional transverse component of the rudder velocity $v_{R}^{\prime}$. This can be calculated from two velocity components, namely:

1. Behind the hull free-stream velocity with pure drift angle (CFD)

\section{Yaw-induced velocity component}

As shown in Fig. 17, the transverse velocities obtained from the CFD analyses are about $15 \%$ of the ship speed for both ships at rudder amidships and decrease toward the ships' centre line $\left(\theta=180^{\circ}\right)$. As expected, it can be observed that the ship drift has a larger effect on the transverse velocity of the upstream blade (e.g. port blade during a drift to port), whereas the downstream blade perceives a straighter flow due to being in the hull's shadow. The flow straightening phenomena become more pronounced as the rudder moves closer to the ship's centreline. The region $160^{\circ}<\theta<200^{\circ}$ spans the propeller wake, where peaks for the rotational velocity induced by the propeller rotation can be seen. It will be appreciated that the highest inflow angles occur for large in angles - e.g. $\delta=-30 \mathrm{deg}$, or $\theta=60 \mathrm{deg}$ in Fig. 17 for the port blade. Moreover, the function appears to be pointsymmetric, with the asymmetries probably given by the propeller action. Taking these results into account and introducing the dependency on GR angles $\delta_{P}$ and $\delta_{S}$ and the drift angle $\beta$, the general equations for normalised transverse velocity can be described for port and starboard blades as follows:

$$
\begin{aligned}
& v^{\prime *}{ }_{R P}=0.15-0.0573 \cdot \delta_{P}+0.5730 \cdot \beta \\
& v^{\prime *}{ }_{R S}=-0.15+0.2865 \cdot \delta_{S}+0.2865 \cdot \beta
\end{aligned}
$$

where the rudder and drift angles are expressed in radians. The yaw-induced velocity component is then added as per the following Equations (22):

$$
\begin{aligned}
& v_{R P}^{\prime}=v^{\prime *}{ }_{R P}-\ell^{\prime}{ }_{R} r^{\prime} \\
& v_{R S}^{\prime}=v^{\prime *}{ }_{R S}-\ell^{\prime}{ }_{R} r^{\prime}
\end{aligned}
$$

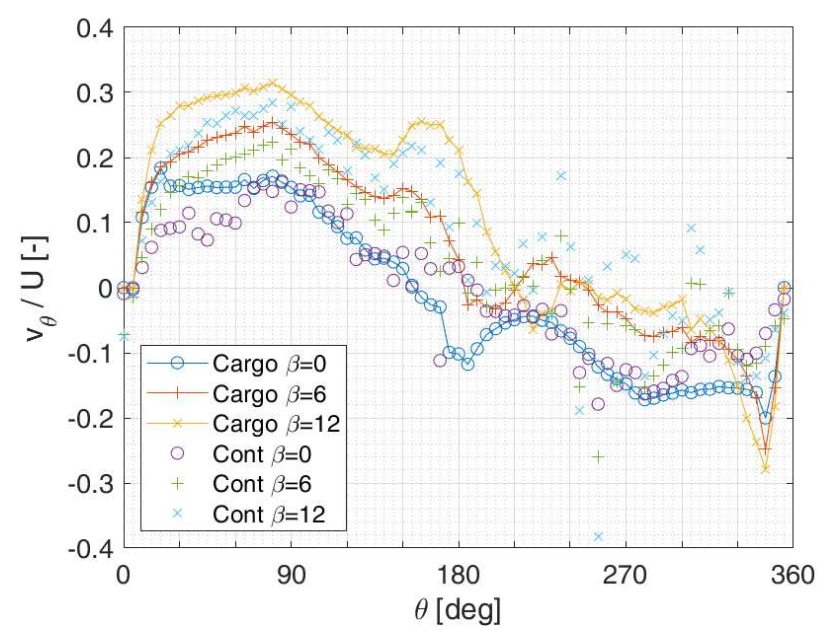

Figure 17. Nondimensional transverse velocities on the probe for the container vessel and the domestic cargo vessel at 0deg drift angle

It is noted that the parametric equations (20) and (21) are valid for the normal operating angle range, i.e. -30deg to $+35 \mathrm{deg}$.

The normal force on each blade can be found by superposition of two components, namely:

1. Force generated by the portion of rudder blade outside of the propeller slipstream and

2. Force generated by the portion of the rudder blade inside the propeller slipstream. 
Taking the port GR blade as an example, the normal force is defined as:

$$
F_{N P}=F_{N P o s}(1-\mu)+\mu F_{N P i s}
$$

where $\mu$ is the covered area ratio defined in Eq. (15) and $F_{N P O S}$ and $F_{N P i s}$ are the forces components outside and inside the propeller slipstream respectively. In analogy with Equations (7) and (9), these are defined as:

$$
\begin{aligned}
& F_{\text {NPos }}=0.5 \rho A_{R} U_{R P o s}^{2} f_{\alpha} \sin \alpha_{R P o s} \cos \alpha_{R P o s} \\
& F_{N P i s}=0.5 \rho A_{R} U_{R P i s}^{2} f_{\alpha} \sin \alpha_{R P i s} \cos \alpha_{R P o s}
\end{aligned}
$$

A $\sin \alpha_{R} \cos \alpha_{R}$ formulation is here used to better describe the rudder blade lift in relation to the stall according to experimental evidence [16]. For large in angles, the inflow angle at the rudder is maximised, raising potential stalling problems. However, model test results have shown that in such case the small gap between the hull and the GR blade's leading edge ( 0.9 chord lengths on average, 0.6 minimum) generates strong interactions with the hull. Due to this effect, the force is amplified and the stall is delayed beyond $45 \mathrm{deg}$ of inflow angle, justifying the simple stall model provided by the $\sin \alpha_{R} \cos \alpha_{R}$ formulation.

The inflow velocities at the port rudder blade outside and inside the slipstream are respectively expressed as:

$$
\begin{aligned}
& U_{R P o s}=U \sqrt{u_{R P o s}^{\prime 2}+v_{R P}^{\prime 2}} \\
& U_{R P i s}=U \sqrt{u_{R i s}^{\prime 2}+v_{R P}^{\prime 2}}
\end{aligned}
$$

where $U$ is the ship speed. Similarly, the inflow angles on the port blade are defined in analogy with eq. (8) and (9) as:

$$
\begin{aligned}
& \alpha_{R P o s}=\delta_{P}-\tan ^{-1}\left(\frac{v_{R P}^{\prime}}{u_{R P o s}^{\prime}}\right) \\
& \alpha_{R P i s}=\delta_{P}-\tan ^{-1}\left(\frac{v_{R P}^{\prime}}{u_{R i s}^{\prime}}\right)
\end{aligned}
$$

The lift gradient coefficient $f_{\alpha}$ was estimated using the relation $6.13 \lambda /(2.25+\lambda)$, with $\lambda$ being the aspect ratio of the rudder blade [23].

The formulation of the propeller wake fraction $w_{P}$ also needed a revision, as the standard $\mathrm{MMG}$ equation cannot hold due to the duct effect induced by the GR. The wake fraction was investigated from towing tank experiments (see 4.1) and a new relationship is proposed given by eq. (30) as function of the local drift angle in radians:

$$
w_{P}\left(\beta_{R}\right)=w_{P 0}-0.6566 \cdot \beta_{R}^{2}
$$

where $w_{P 0}$ is the Taylor effective wake fraction at zero drift angle.

Finally, owing to the wide variation of relative position between rudder blades and hull, and the significant consequence on the increase of lateral force, it was necessary to investigate if different rudder-hull interactions occur depending on whether the blades are closer or farther from the hull. These were investigated by means of the captive model tests presented in Section 4.1.

Based on the above-described formulation, a manoeuvrability program was thus written in VBA code to simulate the standard ITTC Z-Tests and Circle Test for both Conventional Rudder and Gate Rudder systems. The program comprises an Excel user interface for data input and output analysis and an integrated VBA code handling the iterative solution of the fundamental equations. The first core part of the code is concerned with the determination of the hydrodynamic forces acting on the hull, propeller and rudder components. The second part handles the initialisation, a Runge-Kutta discretisation method and the controls of simulation and virtual ship. The input data are initialised from the user interface depending on whether the rudder mode is set to simulate a conventional (CR), a high-lift flap rudder (FR) or the Gate Rudder (GR) system.

\subsection{Captive model tests}

Purposely designed Captive Model Tests (CMT) were conducted at the Seakeeping and Manoeuvring Basin of Kyushu University, Japan. The experiments allowed the analysis of the manoeuvring parameters - e.g. hull derivatives and parameters of the GR. The CMT test matrix is reported in Table 5. The rudder forces of the starboard side rudder were measured simultaneously with the 3 components of the hull forces. The focus of the experimental campaign was mainly devoted to the effect of the rudder forces and interactions with the hull compared to those of conventional rudders.

Table 5. CMT test matrix

\begin{tabular}{|l|l|l|l|}
\hline Test & \multicolumn{1}{|c|}{$\boldsymbol{r}^{\prime}$} & \multicolumn{1}{c|}{$\boldsymbol{\beta}$} & \multicolumn{1}{c|}{$\boldsymbol{\delta}$} \\
\hline Pure drift & 0 & $\begin{array}{l}-20,-10,0,3,6, \\
9,10,12,20\end{array}$ & 0 \\
\hline Pure yaw & $0.2,0.6$ & 0 & 0 \\
\hline Drift and yaw & $0.2,0.6$ & $-10,10$ & 0 \\
\hline Pure rudder & 0 & 0 & $\begin{array}{l}-30,-20,-10,0, \\
15,30,45,60\end{array}$ \\
\hline
\end{tabular}


Figure 18 shows the results of the rudder-hull interaction measurements of side forces and yaw moments in the pure rudder tests. The top plot shows the relationship used to obtain the rudder force increase factor $a_{H}$, which is obtained as in Equation (6) from the slope of the nondimensional side force $Y^{\prime}$ against $-F^{\prime}{ }_{N} \cos \delta$ [10]. The plot shows that the GR has a weaker interaction with the hull when in the out position (positive angles), whereas it provides a stronger interaction when closer to the hull (in) probably due to the leading edge slat effect. Therefore, two different rudder force increase factors, $a_{H i n}=0.336$ and $a_{\text {Hout }}=0.114$, were defined. In the bottom plot, the nondimensional position of the additional lateral force, $x_{H}$, is obtained from the slope of the nondimensional yaw moment $N^{\prime}$ against $-F^{\prime}{ }_{N} \cos \delta$. The single value of $x_{H}^{\prime}=$ -0.325 was calculated from the slope of the second figure, the nondimensional position of the rudder, $x_{R}^{\prime}=0.49$, and the average $a_{H}$. The single $x_{H}$ value was preferred instead of two separate in and out values to simplify the model after observing the negligible impact of this approximation on all the standard manoeuvres. It was also found that the steering resistance deduction factor had mean value $t_{R}=$ 0.341 .
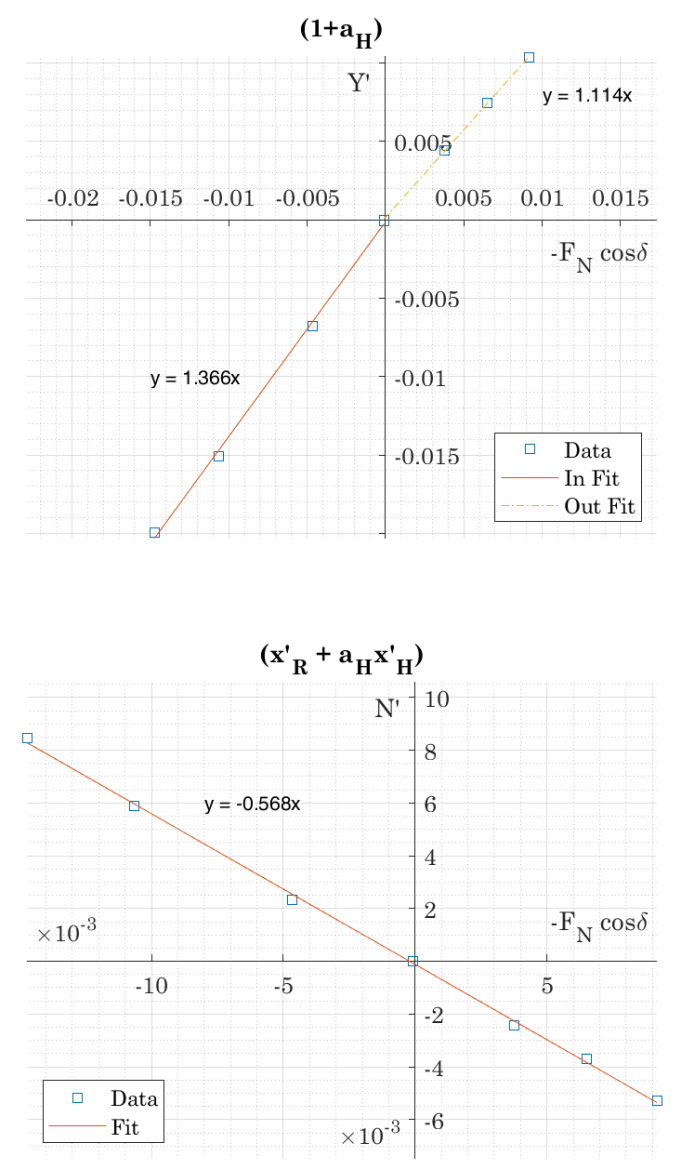

Figure 18. Results of the rudder-hull interaction measurements

\subsection{Towing tank validation}

To validate the parameters adopted in the simulation program and the accuracy of the prediction itself, freerunning tests were conducted at the Seakeeping and Manoeuvring Basin of Kyushu University using a $2.5 \mathrm{~m}$ scaled model of the Domestic Cargo vessel as shown in Fig. 19. Zig-zag tests and turning circle manoeuvres were performed as standard.

There were two significant restrictions during the freerunning tests which were associated with the tank length and the measurement instrumentation. Due to the short length of the tank, it was not possible to cover the $2^{\text {nd }}$ overshoot angle. Secondly, the relatively larger size of the rudder steering unit only allowed for the starboard side blade to be controlled and measured, so that the port blade had to be manually fixed before each run. Bearing these limitations in mind, the test matrix is reported in Table 6. On the one hand, the limitations implied that the zig-zag tests had to be conducted with the port rudder angle fixed at $0 \mathrm{deg}$. On the other hand, the turning circles had to start with the port blade fixed to the final angle of each run - i.e. $+35 \mathrm{deg}($ out $)$ and $-30 \mathrm{deg}$ (in) for the $+35 \mathrm{C}$ and $-35 \mathrm{C}$ tests respectively, as reported in Table 6 . To compensate the obvious initial yaw that would be caused by the fixed rudder angle of the portside blade, the experiment was started with the starboard blade having a helm equal and opposite to the port blade. For instance, the $+35 \mathrm{C}$ test was commenced with the port blade manually fixed at $+35 \mathrm{deg}$ and the starboard blade at $+35 \mathrm{deg}$ (remotely controlled). At this point, the model travels in a straight motion. Then, the starboard blade is helmed at $-30 \mathrm{deg}$, initiating the circle manoeuvre. The zero of the circle test is set at the time the helm order of the starboard blade is given and the model initiates the turn. During the free-running tests, the ship motions were captured by optical means to allow the free motion responses of the model.

Table 6. Test matrix. GR angles follow the GR sign convention

\begin{tabular}{|c|cc|}
\hline Test & Port blade & Starboard blade \\
\hline+10 zig-zag & 0 & -10 \\
-10 zig-zag & 0 & 10 \\
+20 zig-zag & 0 & -20 \\
-20 zig-zag & 0 & 20 \\
+35 circle & 35 & -30 \\
-35 circle & -30 & 35 \\
\hline
\end{tabular}

Figures 20 through 23 show representative manoeuvring simulations together with the experimental measurements. The figures generally show that the simulations closely agree with the experiments and capture the trajectory of the vessel during the manoeuvre except for the heading time 
series of Fig. 20, where the cited experimental limitations exposed strong asymmetries. In spite of the apparently large discrepancies in lift and drag forces on the rudder blades between model and simulationand and of the experimental limitations, the differences in overshoot angle and tactical diameter are relatively small, indicating a low sensitivity of the manoeuvres for significant scale effects [15], [24].

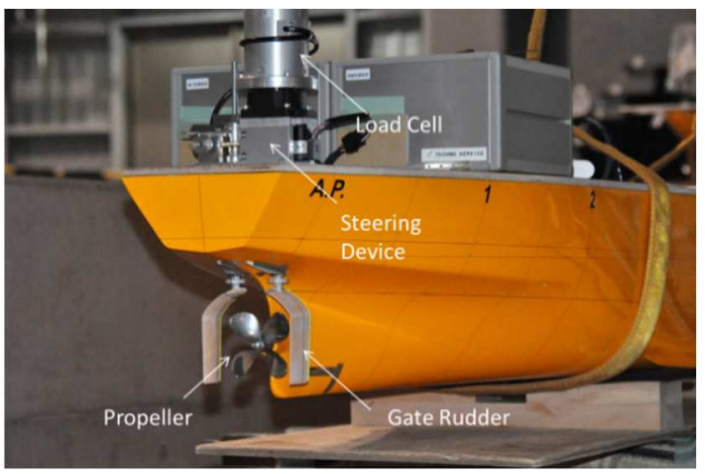

Figure 19. 2.5m wooden model of the Domestic Cargo vessel used in the towing tank tests
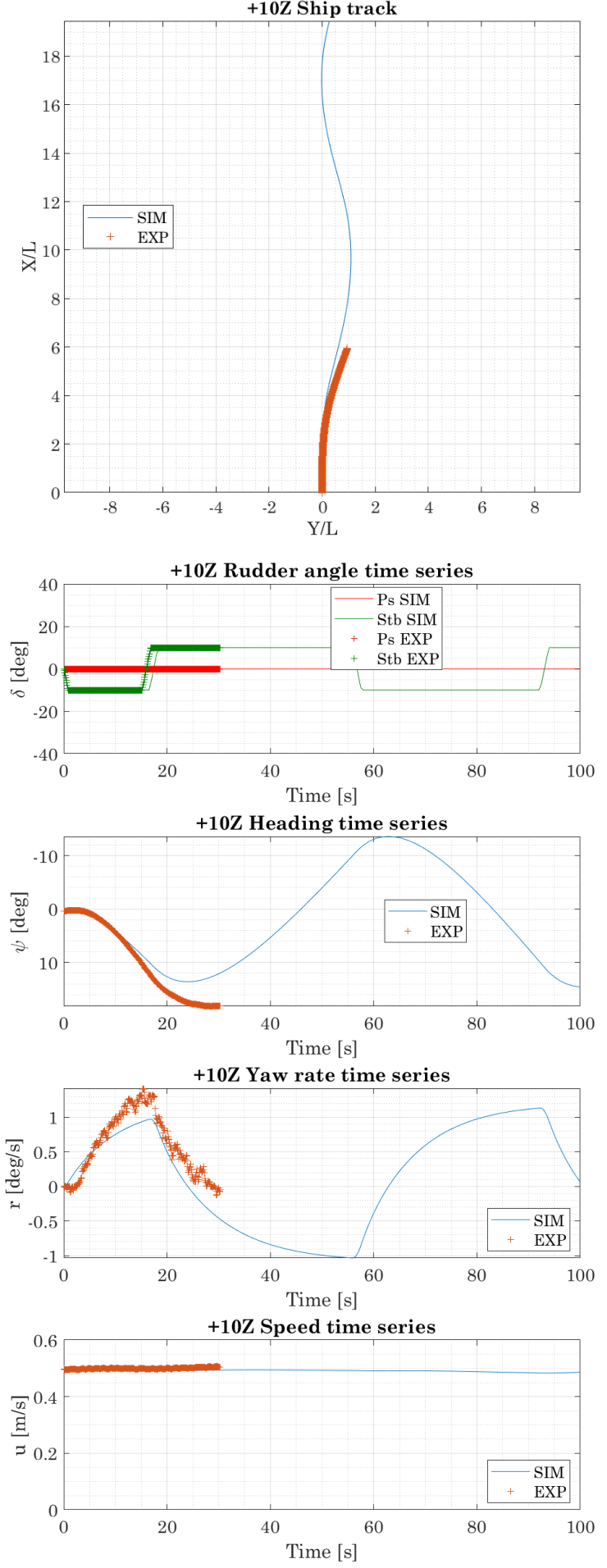

Figure 20. Ship track and time series for the starboard 10deg zig-zag test $(+10 \mathrm{Z})$ 

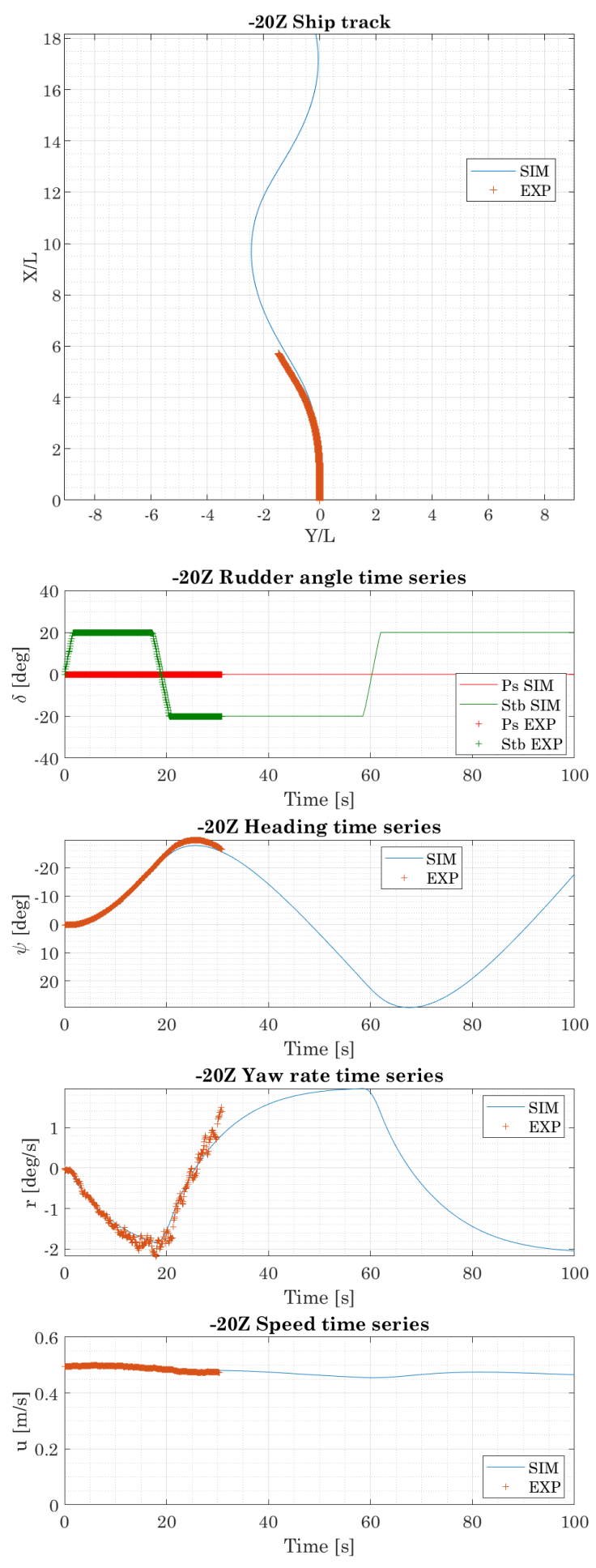

Figure 21. Ship track and time series for the port $20 \mathrm{deg}$ zigzag test (-20Z)
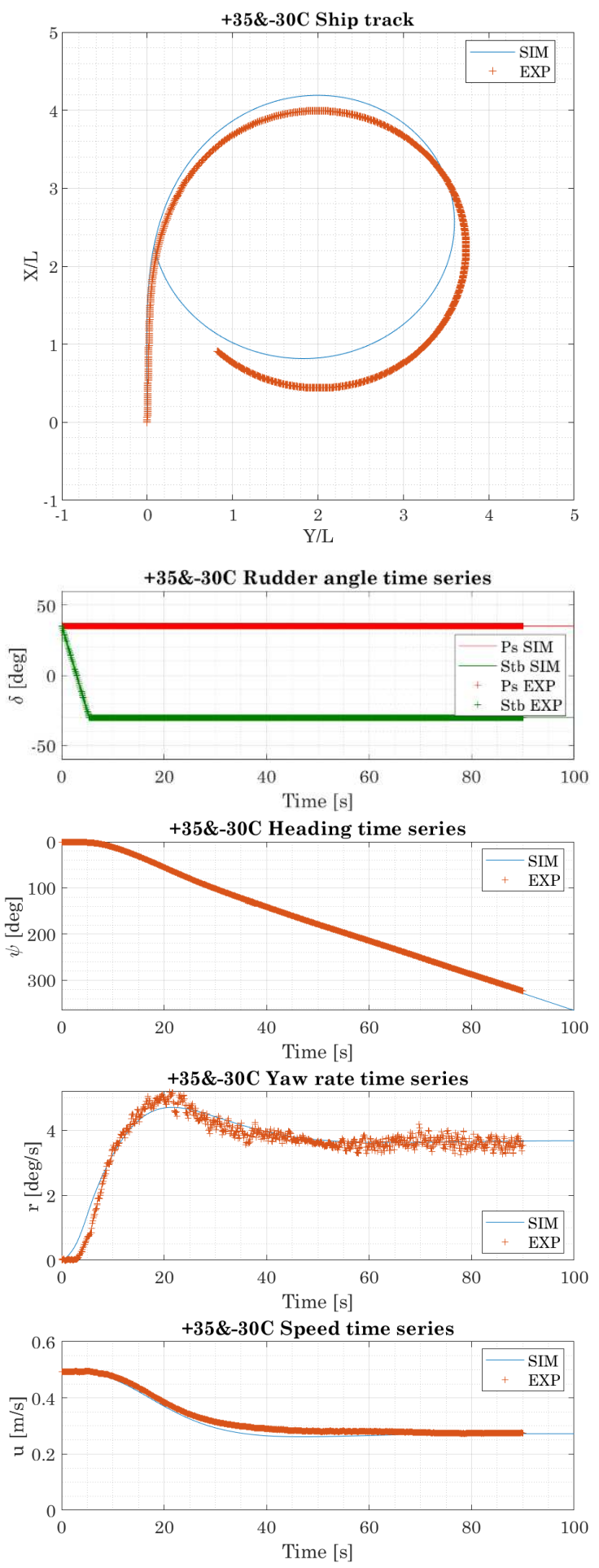

Figure 22. Ship track and time series for the starboard 35deg circle test $(+35 \mathrm{C})$. Port and starboard target angles are given in the figure titles 

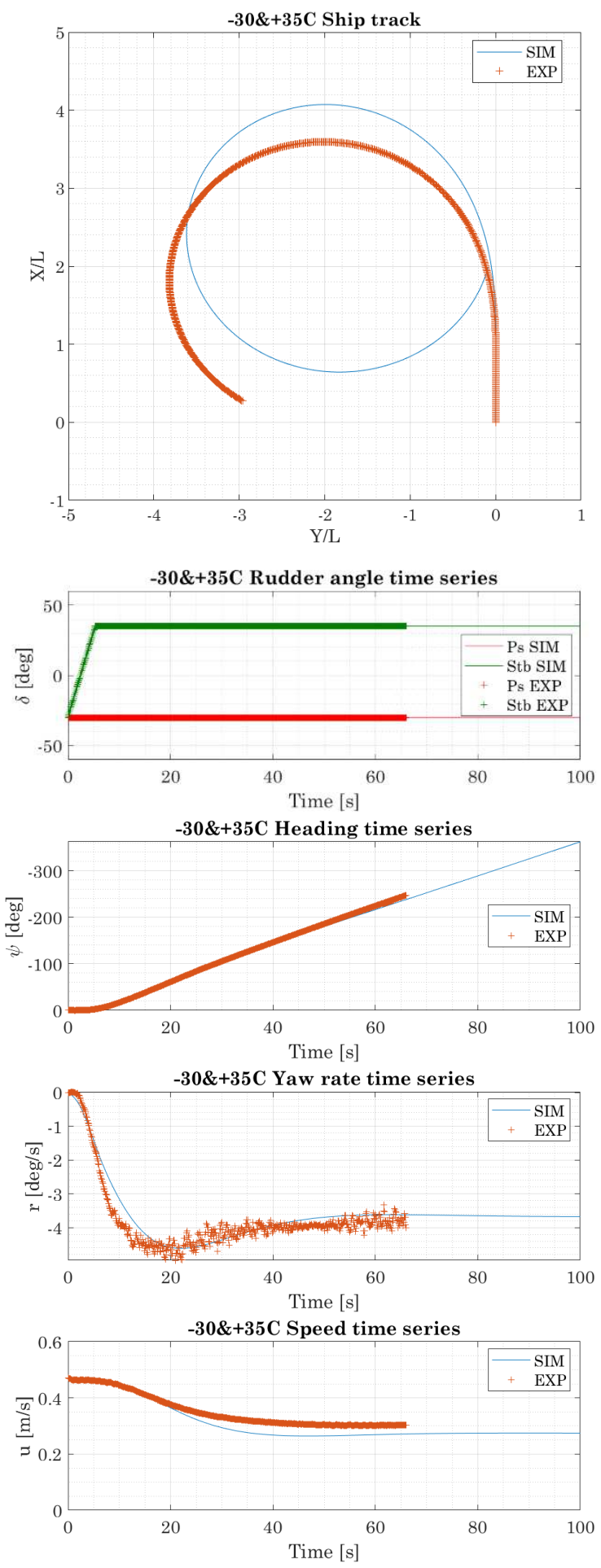

Figure 23. Ship track and time series for the port 35deg circle test (-35C). Port and starboard target angles are given in the figure titles

\section{FULL-SCALE TRIALS}

Manoeuvring Sea Trials (ST) were conducted on two sister feeder container ships, the Sakura and the Shigenobu (details in Table 3). The latter was fitted with the first-ever full-scale GR system while Sakura was with a competitive high-lift Flap Rudder (FR) system (Fig. 24). The ships are identical except for their steering gear, thus allowing an accurate comparison of two different rudder systems. The full-scale measurements here reported serve a double purpose. Firstly, they strengthen the confidence in the validity of the GR manoeuvrability model presented in the previous section, despite no scale effect correction was applied. Secondly, allow a comparison the GR manoeuvrability characteristics with that of a highperformance rudder.

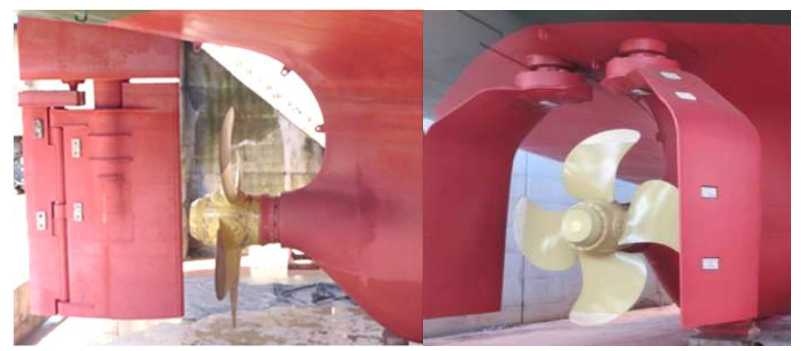

Figure 24. Steering systems of the Sakura (left) and Shigenobu (right)

The full-scale trials were conducted according to recognised standard procedures at Setouchi Sea, Japan, at different times. Weather conditions were deemed fair, with no tide current and wind speeds no higher than $6 \mathrm{~m} / \mathrm{s}$, so that only small corrections for the weather were applied according to the standards [25]-[27]. The manoeuvres performed during the ST and reported in this paper are listed as follows:

- Zig-zag manoeuvre at 10deg helm angle

- Turning circles at $35 \mathrm{deg}$ helm angle

- Spiral manoeuvre

In addition, a pivot turning circle from dead in the water with maximum helm angles was also performed to investigate the GR's in-harbour manoeuvrability. Due to restrictions in the on-board automatic reporting system, only certain variables could be exported and analysed.

Fig. 25 shows the results of the full-scale 10deg to port zigzag (-Z10) manoeuvre at 16kn (220 RPM). The top plot compares the simulations and full-scale measurements of the GR [27] and the full-scale measurements of the FR [25]. The bottom plot compares the simulations and fullscale measurements of the Shigenobu (GR), since the speed of the Sakura (FR) was not available. In this manoeuvre, the two GR blades are helmed with the same angles, but with different signs according to the GR angle sign convention (Fig. 12). This means that in the $-\mathrm{Z} 10$ manoeuvre the first helm angles will be -10deg for the port 
blade and 10deg for the starboard blade respectively. The top plot only shows the port rudder angle. It is first noticed that the manoeuvre is well reproduced by the simulator and shows very good agreement between the variables. On the other hand, the FR measurements show a slightly higher first overshoot angle followed by a second lower overshoot. The bottom plot shows that the simulations well captured the full-scale speed loss of the Shigenobu. A summary of the $-10 \mathrm{Z}$ test is reported in Table 7.
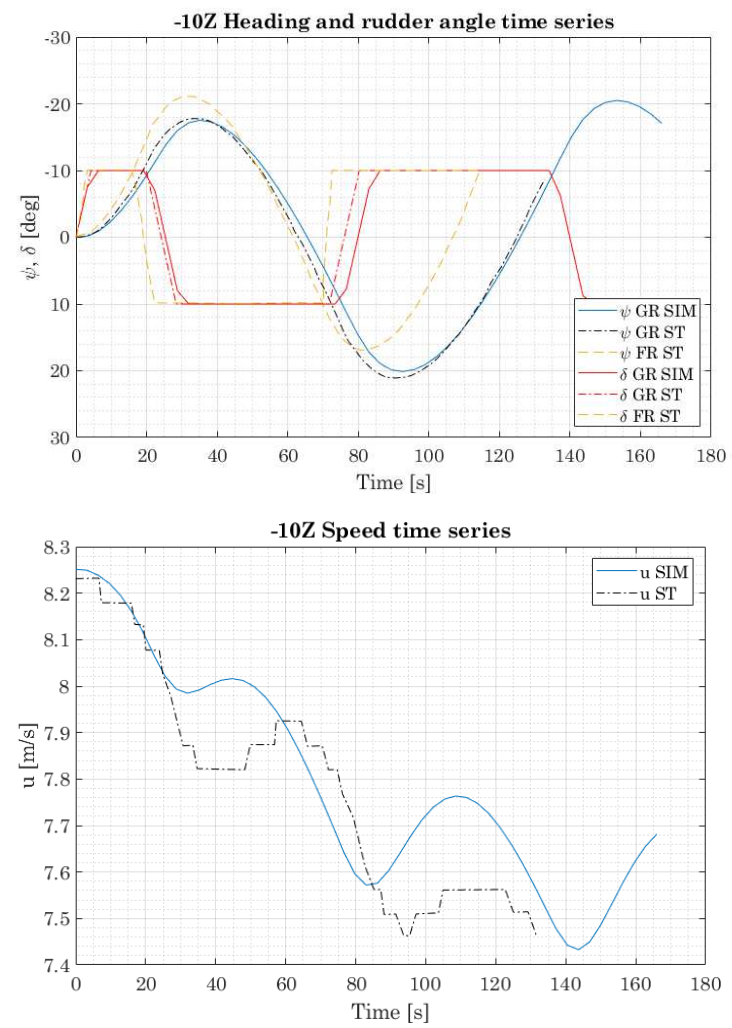

Figure 25. Simulation and full-scale measurement of heading, rudder and speed of the $-10 \mathrm{Z}$ test $@ 16 \mathrm{kn}$ for the

Gate Rudder and the FR (heading and rudder only)

Table 7. Summary of the $-10 Z$ test

\begin{tabular}{|l|c|c|c|}
\hline & $G R$ & $F R$ & IMO criteria \\
\hline $1^{\text {st }} O S A$ & $7.8^{\circ}$ & $11.1^{\circ}$ & $10^{\circ}$ \\
\hline $2^{\text {nd }} O S A$ & $11.1^{\circ}$ & $7.0^{\circ}$ & $25^{\circ}$ \\
\hline
\end{tabular}

Figure 26 shows the ship track of GR and FR in -35C turning circle manoeuvres from an initial speed of $9 \mathrm{kn}$ (195 RPM). The lengths are non-dimensionalised by the ship length. This manoeuvre is performed helming the port and starboard GR blades to -30deg (maximum in angle) and $35 \mathrm{deg}$ (out) respectively. The figure shows that both ships perform within the IMO limits $(5 \mathrm{~L}$ tactical diameter and $4.5 \mathrm{~L}$ advance). It is then noticed that the FR provides, in general, stronger steering forces providing a smaller turning diameter. Conversely, the GR grants a smoother inception and evolution of the side forces and yaw moments. As mentioned in Section 4, the initial benefit of the GR is later partially lost as the blades operate in a deviated flow field at larger helm angles. Conversely, the FR operates always in the wake of the propeller, so that its effectiveness remains high. A summary of the $-35 \mathrm{C}$ test is given in Table 8 .

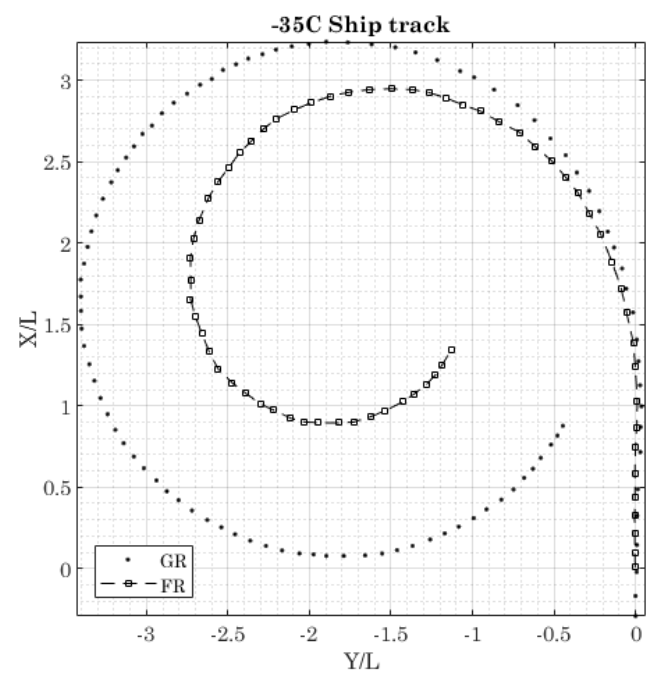

Figure 26. Comparison of full-scale measurements of the GR and the FR conducting the -35C test @9kn

Table 8. Summary in ship lengths of the $-35 C$ test

\begin{tabular}{|l|c|c|c|}
\hline & $G R$ & $F R$ & IMO criteria \\
\hline $\begin{array}{l}\text { Tactical } \\
\text { Diameter }\end{array}$ & 3.2 & 2.6 & 5 \\
\hline Advance & 3.3 & 2.8 & 4.5 \\
\hline
\end{tabular}

The Shigenobu's (GR) ship track and yaw rate for the same $-35 \mathrm{C}$ turning circle of Fig. 26 are presented in Fig. 27 and 28. The graphs show the comparative results between the simulations (SIM) and the full-scale sea trials (ST). The manoeuvrability model appears to predict well the overall manoeuvre in spite of an underestimation of the maximum transfer. This might be caused by the scale effects which are not accounted for in the model. The size and shape of the final diameter are however captured. Similarly, the nondimensional yaw rate (Fig. 28) is reproduced well by the simulations, as the model suitably represents the transient rate and settles at the correct asymptotic value. 


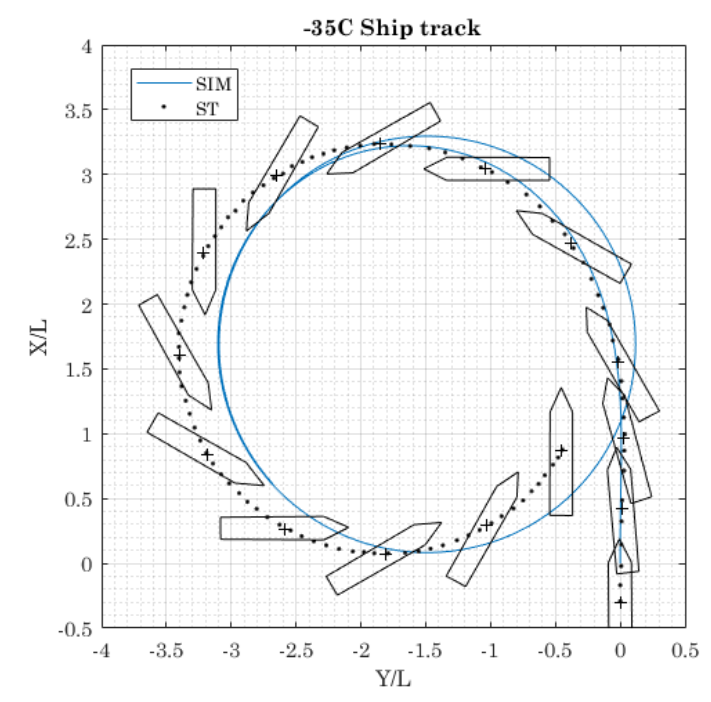

Figure 27. Comparison of simulation and full-scale measurements of the nondimensional ship track during the GR's -35C test @9kn

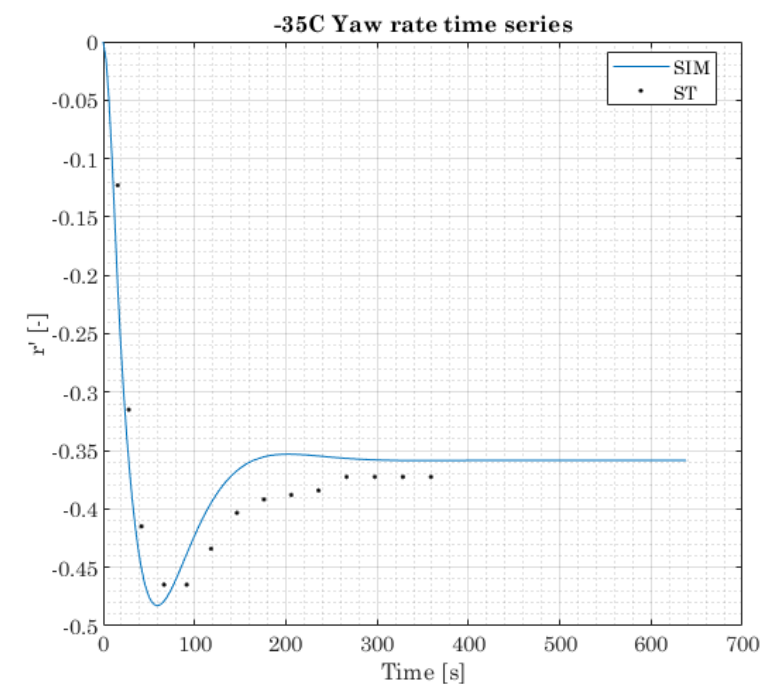

Figure 28. Comparison of simulation and full-scale measurement of nondimensional yaw rate during the GR's 35C test @ $9 \mathrm{kn}$

Although only the ship track was available for the Sakura (FR), the ship track of the $-35 \mathrm{C}$ manoeuvre of Fig. 26 is also shown in Fig. 29 for a cross-comparison with the manoeuvrability model. In this case, the simulator was initialised with all the values and parameters of the FR, showing a reasonable agreement between simulation and measurements. However, at the current stage of development of the model, the discrepancies of the prediction could indicate an overestimation of rudder forces, or inaccurate modelling of hull or interaction effects. It must be, however, noted that the FR forces were described in the model with larger approximation compared to the GR.

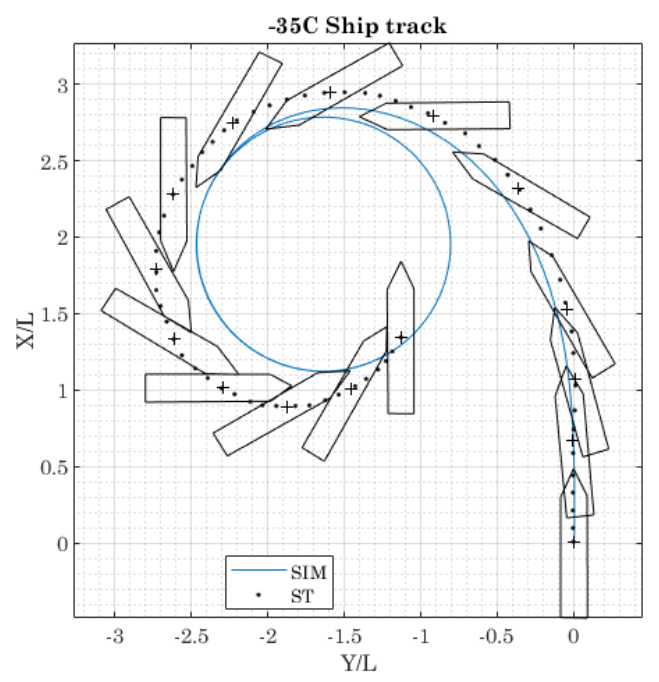

Figure 29. Comparison of simulation and full-scale measurement of the yaw rate during the FR's -35C test (a) 9 kn

The spiral test is usually performed to inspect the performance of the vessel-rudder system particularly at low angles to verify the course stability of the vessel. The results of the full-scale spiral tests conducted by both ships @ 16kn (220 RPM) are presented in Fig. 30. The yaw rate is nondimensionalised by the actual velocity. The full-scale measurements and the simulations of the Shigenobu (GR) are plotted together with the Sakura (FR) measurements. The nondimensional yaw rate allows here to better observe the differences between the turning performance of the two ships in accordance with the different steering system. For small rudder angles (i.e. -5 to 5 ) the plot concerns the ships' course keeping stability. In this range, the GR provides milder turning forces, ensuring a more sensitive steering command. As expected, the FR delivers overall stronger steering forces, which leads to a steeper slope of the curve at low rudder angles. At large rudder angles, both rudders grant the fulfilment of the IMO limits (see Table 8), although the FR achieves tighter turning circles due to its effectiveness and the significant speed drop it induces. The overall behaviour of the Shigenobu (GR) is described reasonably well by the simulator, seemingly confirming the effectiveness of the manoeuvrability model for the GR system. The simulations tend to slightly underestimate the stiffness of the vessel in the linear region or to overestimate the effects of the GR at low helm angles. The simulator also succeeds at reasonably describing the behaviour of the Sakura (FR), although the effectiveness of the FR is overestimated at the higher rudder angles. This is deemed however acceptable according to the earlier remarks regarding the accuracy of the FR forces in the model. 


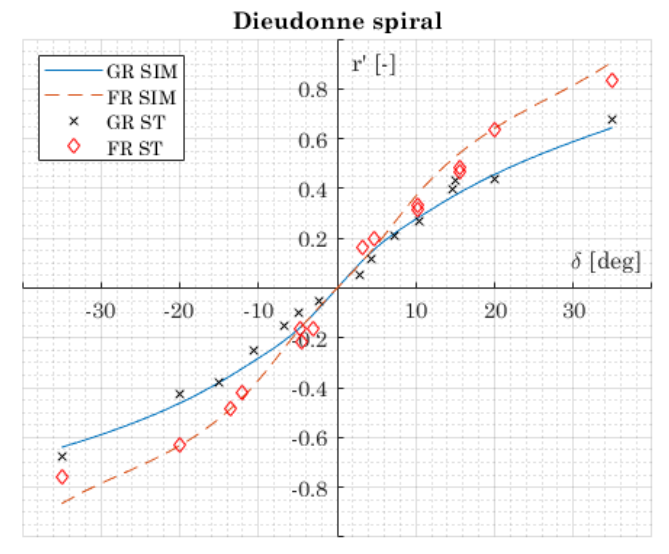

Figure 30. Comparison of simulation and full-scale measurements of the GR and of the FR conducting the spiral test @16kn

Some low-speed manoeuvres (out of the scope of the manoeuvring simulator) were also conducted, similar to the Accelerating Turning Test [28]. Because of its particular configuration, the GR is capable of very large rudder angles that allow very efficient low speed manoeuvring. One of these configurations is the crabbing mode, illustrated in Fig. 3, which is used when the ship is still in the water or at the very low speeds used for harbour manoeuvring. In the crabbing mode, the blade 'inside' the turn (i.e. port blade in a port turn) is helmed at $110 \mathrm{deg}$ and the other at $60 \mathrm{deg}$. The propeller is then engaged, allowing the GR to develop very strong side forces. These forces are similar to those exerted by a conventional stern thruster and are employed to turn the vessel on the spot during harbour manoeuvring. Figure 31 shows this kind of manoeuvre for the Shigenobu (GR) and the Sakura (FR), the latter using the maximum feasible rudder angle of $-70 \mathrm{deg}$. The manoeuvre is conducted from dead in the water without thrusters and giving the propeller speed of 194 RPM. It is apparent that the inception of the GR action occurs immediately as soon as the propeller is engaged and does not need the ship to have the forward speed to develop the necessary steering forces. This translates in a smaller maximum turning diameter (1.4L), a shorter maximum advance (1.2L) and most importantly a much lower space usage than the FR. While the FR handles the Sakura more similarly to a turning circle, i.e. keeping the trajectory on the port side of the initial position, the GR displaces the Shigenobu laterally to starboard, and later to port. Large drift angles are generated that shift the ship's pivot point and allow turning on the spot much closer to the starting position.

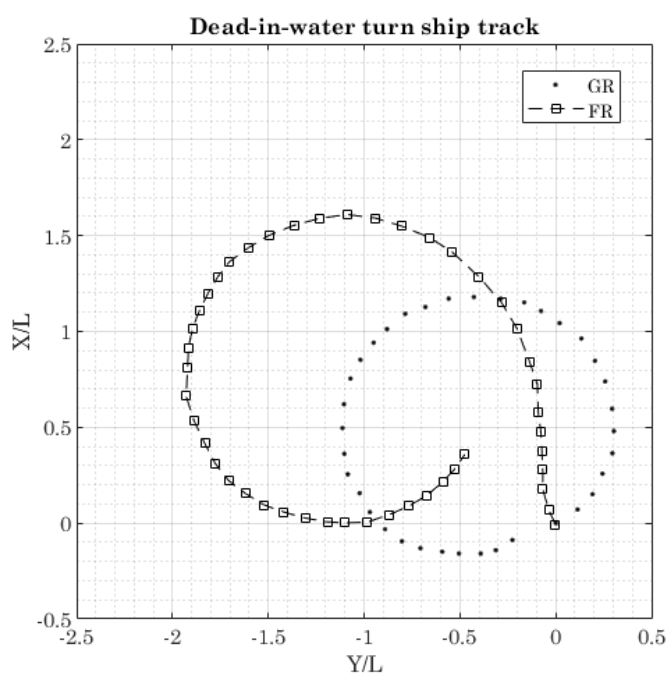

Figure 31. Comparison of turning circle full-scale manoeuvres from dead in the water between the Gate Rudder (GR) and the Flap Rudder (FR)

The full-scale manoeuvres above presented demonstrated the manoeuvrability capabilities of the GR system. They at first showed that the manoeuvring model adopted to simulate the GR forces well represents the full-scale dynamics at cruise speed. The model still suffers some discrepancies from the measurements, which opens for further work.

On the one hand, it should be borne in mind that the GR's manoeuvring performance is here compared to a competitive steering system (i.e. high-lift FR), which bears significant operational advantage over a conventional rudder. In fact, the full-scale measurements show that the GR generates overall lower steering forces than the FR at higher speeds. On the other hand, the advantages of the manoeuvring performance profile of the GR becomes apparent both at low speeds and during normal navigation. At low speeds, the GR is capable of generating very strong side forces, which are essential for harbour/berthing manoeuvres (Fig. 31). At cruise speed, the GR generates manageable course-keeping actions that are convenient for course-stable ships. In practice, commercial ships need milder steering forces at navigational speed and seek higher effectiveness at the lower speeds for harbour manoeuvring. In this perspective, the GR's manoeuvring performance can be advantageous.

\section{CONCLUSIONS}

This paper attempted to address the manoeuvring performance of ships fitted with the Gate Rudder systems for the first time. In doing so, the MMG standard manoeuvrability prediction method was reviewed and modified to accommodate the prediction formulations for the Gate Rudder system. This has been successfully achieved and led to the development of a simulation software based on numerical, experimental and full-scale techniques. The following conclusions were reached: 
- Detailed CFD analyses were conducted on two commercial hullforms to understand and parametrise the flow field around the Gate Rudder blades by considering the interaction between the hull and the propeller. Based on these analyses, generalised equations were devised to calculate the velocity components at any helm position of the gate rudder and a wide range of realistic drift angles.

- A modified MMG prediction method was then tailored to the environment of a simulation program which is able to predict the manoeuvring performance of Gate Rudders for the standard IMO recommended manoeuvres.

- Captive model tests and free-running manoeuvring tests were conducted to validate the developed simulation program. Experimental results showed that the hull-rudder interaction is very strong when the rudder blade is closer to the hull. This leads to a higher additional steering force and to a leading-edge slat effect which increases the rudder force and postpones the stall angle.

- Comparison between simulations and experiments showed that the simulation model is able to capture the manoeuvring motions of a vessel equipped with a Gate Rudder with reasonable accuracy. However, due to the limitations of the experimental campaign, further validation work is required to finalise the model validation.

- Full-scale manoeuvrability trials were conducted on a feeder container ship equipped with the firstever Gate Rudder system. The full-scale measurements were compared with both simulations and with the full-scale measurements of a sister ship fitted with a high-lift flap rudder. The analyses showed that the Gate Rudder generates milder steering forces compared to a high-lift flap rudder at cruise speed. The steering capabilities of the GR at zero speed are however superior and entail excellent harbour manoeuvring performance.

- The full-scale measurements also confirmed the simulation predictions, which could reproduce the manoeuvres with good accuracy.

- Further work is needed to investigate the scale effects to which the Gate Rudder is subjected in consideration of the flow conditions in which it operates.

\section{ACKNOWLEDGEMENTS}

The Authors gratefully acknowledge Kamome Propellers for the technical and financial support given to the advancement of the Gate Rudder project. They also thank the members of Kyushu University for conducting the manoeuvrability tests, which composed an essential part of this study. This part of the research was supported by the Nippon Foundation.

\section{REFERENCES}

[1] J. S. Carlton, Marine propellers and propulsion, 3rd ed. Amsterdam, NL: Butterworth-Heinemann, 2012.

[2] B. Schuiling and T. van Terwisga, 'Hydrodynamic working principles of Energy Saving Devices in ship propulsion systems', International Shipbuilding Progress, vol. 63, no. 3-4, pp. 255-290, Jun. 2017, doi: 10.3233/ISP-170134.

[3] N. Sasaki, M. Atlar, and S. Kuribayashi, 'Advantages of twin rudder system with asymmetric wing section aside a propeller: The new hull form with twin rudders utilizing duct effects', Journal of Marine Science and Technology, vol. 21, no. 2, pp. 297-308, Jun. 2016, doi: 10.1007/s00773-015-0352Z.

[4] N. Sasaki, 'ZEUS and NOAH projects of NMRI', in Proc. of the 3rd International Symposium on Marine Propulsors (SMP'13), Lauceston, AU, 2013.

[5] N. Sasaki, S. Kuribayashi, and M. Atlar, 'GATE RUDDER', in Proc. of the 3rd International Symposium on Naval Architecture and Maritime (INT-NAM 2018), Istanbul, TR, 2018.

[6] N. Sasaki and M. Atlar, 'Investigation into the Propulsive Efficiency Characteristics of a Ship with the GATE RUDDER ${ }^{\circledR}$ Propulsion System', in Proc. of the A. Yücel Odabaşı Colloquium Series: $3 r d$ International Meeting, Istanbul, TR, Nov. 2018.

[7] S. Turkmen, M. Fukazawa, N. Sasaki, and M. Atlar, 'Cavitation model tests and full-scale review of the first Gate Rudder system installed on the 400TEU container ship', in Proc. of the A. Yücel Odabaşı Colloquium Series: 3rd International Meeting, Istanbul, TR, Nov. 2018.

[8] N. Yilmaz, S. Turkmen, B. Aktas, P. Fitzsimmons, N. Sasaki, and M. Atlar, 'Tip Vortex Cavitation Simulation of a Propeller in a GATE RUDDER ${ }^{\circledR}$ System', in Proc. of the A. Yücel Odabaşı Colloquium Series: 3rd International Meeting, Istanbul, TR, Nov. 2018.

[9] DNV, 'Ship manoeuvrability: Guidelines for rudder area', Det Norske Veritas Classification, Casualty Information, 1995.

[10] H. Yasukawa and Y. Yoshimura, 'Introduction of MMG standard method for ship maneuvering predictions', Journal of Marine Science and Technology, vol. 20, pp. 37-52, 2015.

[11] M. Hirano, 'A practical calculation method of ship maneuvering motion at initial design stage', Journal 
of the Society of Naval Architects of Japan, vol. 147, pp. 68-80, 1980.

[12] I. Y. Gong, C. G. Kang, Y. G. Kim, Y. B. You, D. Huh, and Y. H. Kim, 'The Influence of rudder Area on the Manoeuvrability of a Ship with Large Beam to Draft Ratio', in Proc. of the 6th International Symposium on Practical Design of Ships and Mobile Units (PRADS'95), Seoul, KR, 1995.

[13] A. F. Molland and S. R. Turnock, Marine rudders and control surfaces: principles, data, design and applications. Amsterdam; London: Elsevier/Butterworth-Heinemann, 2007.

[14] S. Turkmen, A. Carchen, N. Sasaki, and M. Atlar, 'A new energy saving twin rudder system - Gate rudder', in Proc. of the International Conference on Shippping in Changing Climate, Glasgow, UK.

[15] A. Carchen, W. Shi, N. Sasaki, and M. Atlar, 'A prediction program of manoeuvrability for a ship with a Gate Rudder system', in Proc. of the 2nd International 'A. Yücel Odabaşı' Colloquium, Istanbul, TR, Nov. 2016.

[16] A. Carchen, W. Shi, S. Turkmen, and N. Sasaki, 'Development of Gate Rudder Manoeuvring Program based on MMG model', Newcastle University, Newcastle upon Tyne, UK, Confidential industry report, 2017.

[17] S. Turkmen, N. Sasaki, M. Atlar, A. Mikles, and T. Takeda, 'The Gate Rudder application to improve poor course keeping ability of ships', in Proc. of the 2nd International 'A. Yücel Odabaşı' Colloquium, Istanbul, TR, Nov. 2016.

[18] M. Fukazawa, S. Turkmen, A. Marino, and N. Sasaki, 'Full-Scale GATE RUDDER Performance obtained from Voyage Data', in Proc. of the A. Yücel Odabaşı Colloquium Series: 3rd International Meeting, Istanbul, TR, Nov. 2018.

[19] A. Ogawa, K. T., and K. Kijima, 'MMG report-I, on the mathematical model of Ship manoeuvring.', 1977.

[20] JSNAOE, 'Report of Research committee on standardization of mathematical model for ship maneuvering predictions', Japan Society of Naval Architects and Ocean Engineers, 2013.

[21] Y. Yamaguchi, Y. Furukawa, H. Mutou, and K. Kijima, 'Study on Prediction Method of Hydrodynamic Derivatives for Full Ships', Journal of the Japan Society of Naval Architects and Ocean Engineers, vol. 10, pp. 105-113, 2009, doi: 10.2534/jjasnaoe.10.105.

[22] Simcenter, STAR-CCM+ Release Notes. 2018.

[23] H. Fuji and T. Tuda, 'Experimental research on rudder performance - 2nd report', Journal of the Society of Naval Architects of Japan, vol. 110, pp. 31-42, 1961.

[24] N. Sasaki and M. Atlar, 'Scale effect of Gate Rudder', in Proc. of the Sixth International Symposium on Marine Propulsors (SMP`19), Rome, IT, May 2019.
[25] 'Sakura 2510 gross ton container ship. Marine Test Run Report', Yamanaka Shipbuilding Co. Ltd, Sea Trials Report 1051, Jul. 2016.

[26] 'Sakura 2510 gross ton container ship. Marine Test Run Report', Yamanaka Shipbuilding Co. Ltd, Sea Trials Report 1071, 2016.

[27] 'Shigenobu 2510 gross ton container ship. Marine Test Run Report', Yamanaka Shipbuilding Co. Ltd, Sea Trials Report 1070, Nov. 2017.

[28] ITTC, 'Full Scale Manoeuvring Trials Procedure', International Towing Tank Conference, Recommended Procedures and Guidelines 7.5-0402-01, 2002. 
